\title{
Public Health Impact of Legal Termination of Pregnancy in the US: 40 Years Later
}

\author{
John M. Thorp Jr. \\ Department of Obstetrics and Gynecology, School of Medicine, University of North Carolina, Chapel Hill, NC 27599, USA \\ Correspondence should be addressed to John M. Thorp Jr.; john_thorp@med.unc.edu
}

Received 6 September 2012; Accepted 15 October 2012

Academic Editors: M. W. Davies, T. B. Henriksen, and J. Keelan

Copyright (C) 2012 John M. Thorp Jr. This is an open access article distributed under the Creative Commons Attribution License, which permits unrestricted use, distribution, and reproduction in any medium, provided the original work is properly cited.

\begin{abstract}
During the 40 years since the US Supreme Court decision in Doe versus Wade and Doe versus Bolton, restrictions on termination of pregnancy (TOP) were overturned nationwide. The use of TOP was much wider than predicted and a substantial fraction of reproductive age women in the U.S. have had one or more TOPs and that widespread uptake makes the downstream impact of any possible harms have broad public health implications. While short-term harms do not appear to be excessive, from a public perspective longer term harm is conceiving, and clearly more study of particular relevance concerns the associations of TOP with subsequent preterm birth and mental health problems. Clearly more research is needed to quantify the magnitude of risk and accurately inform women with the crisis of unintended pregnancy considering TOP. The current US data-gathering mechanisms are inadequate for this important task.
\end{abstract}

\section{Introduction}

This is a paper written on the 40th anniversary of the US Supreme Court decisions in Roe versus Wade and Doe versus Bolton, in which termination of pregnancy (TOP) restrictions were overturned in all fifty states [1]. This profound sociocultural shift in paradigm and practice has had substantial impact on the lives of women and families in the US and around the world. I am writing from the perspective of an obstetrics and gynecology clinician who has witnessed much of this change during his career. A similar approach from a personal perspective has been used by others on earlier anniversaries [2-7].

Rather than the traditional recitation of limitations at the end of the paper, I have chosen to inform the readers of those $a$ priori. Thus, it can process the evidence cited and conclusions made with those caveats in mind. My hope would be that by providing context from the outset, the reader will be able to more thoughtfully consider the material presented.

First, this is not a systematic review. The relevant literature has not been systematically searched, read by multiple reviewers, graded against a standard, or quantified by metaanalysis. A more subjective and qualitative approach has been chosen. This approach was selected due to the lack of randomized controlled trials for a procedure that cannot be ethically assigned by chance, the inherent difficulties in synthesizing observational data, and the ethical controversy that swirls underneath this topic. Meta-analyses on appropriate outcomes are included in the paper when they have been done.

Next, the paper is geographically parochial and limited to the US. This is due to the limitations of the author and the fact that the US experience is often generalized to the rest of the developed world. Articles from other countries are cited for comparison purposes.

The language used to describe these procedures is fraught with inaccuracy and often overlaps with clinical language used to describe spontaneous pregnancy loss. This is confusing to readers and at times alarming to patients [8]. In this paper the phrase "termination of pregnancy" (abbreviated as TOP) will be used throughout. Use of the abbreviation TOP reflects the editorial policy of the British Journal of Obstetrics and Gynaecology and has been forged after numerous discussions among the editors, to which the author has been privy.

Finally, and most importantly, the ethical principle of autonomy precludes random assignment to TOP. Thus, randomized controlled trials of TOP exposure versus no exposure are impossible to conduct. By definition there is no 
"Level One" or "Grade A" evidence about TOP [9]. Given that women who choose TOP differ from nonpregnant women, those who continue a pregnancy, or those who suffer a spontaneous loss, unmeasured residual confounding plagues investigators and readers trying to understand the biologic implications of the procedure. The appropriate nonexposed control is a source of much disagreement. Whether one discerns true benefit or substantial harm from observational data about TOP, conclusions will always be limited along those lines.

\section{Background}

Before the US Supreme Court decisions mentioned earlier were issued, TOP in the US was severely restricted. With that decision, access to the procedure was greatly expanded and the uptake of TOP procedures was higher than experts predicted. From most recent sources, a prototypical US woman will have two children $[10,11]$. Nearly half of all US women will have an unplanned or unintended pregnancy (when intentionality is broadly defined) and somewhere around half of those will elect to undergo TOP. Thus, between menarche and menopause, in the US, one out of three women will undergo TOP. This makes TOP "one of the most common medical interventions" [12-15].

In the US, approximately 1.2 million TOPs were performed in 2009, while there were 4.5 million live births [13]. Around $90 \%$ of TOPs in the US will be done in the first trimester, with the remainder in the second and third trimesters. Around 1-2\% of TOPs in the US are done because of serious maternal illness, such as cancer or pulmonary hypertension, or an abnormality detected in the fetus, such as trisomy or neural tube defect [14]. Until the past decade, almost all TOPs in the US were performed surgically. Since 2000, medical TOP has become more widely used, building on experience from Western Europe. Medical TOP involves use of the progesterone antagonist mifepristone and the prostaglandin misoprostol. Around $10 \%$ of TOPs in the US are completed medically $[16,17]$.

\section{Epidemiology}

Unlike numerous other countries, the US does not have a systematic method of keeping track of TOP procedures [18$22]$. TOPs are not registered by the government, and there is no mandatory reporting so the true incidence cannot be ascertained. Moreover, TOPs cannot be linked to other sources of health data such as birth or death certificates, thereby making precise calculation of mortality rates or subsequent birth outcomes impossible. This lack of registration of TOP in the US means that observational data from other countries is more reliable in determining short- and longterm health effects. To quote a famous US women's health epidemiologist, the current situation could be described as "garbage in, garbage out" [23].

Two proximate data sources are used in the US by those interested in TOP epidemiology. The estimated number of TOP procedures in the US is obtained from periodic surveys of all identifiable TOP providers by the Guttmacher Institute. Reporting is voluntary and the surveys are done at irregular intervals up to five years apart. The Guttmacher Institute has a clear political agenda and anyone perusing their website would be hard pressed to not describe it as an advocacy group $[24,25]$.

The second source is the annual "abortion surveillance report" amalgamated by the US Centers for Disease Control (CDC). Beginning in 1969, state health departments have voluntarily provided annual reports on TOP procedures and patients. These data are incomplete due to the wide variability in state requirements for reporting of TOP procedures, the voluntary nature of participation with some states choosing to not do so periodically, marked variation in the information each state obtains, and the lack of specific funding for TOP data accumulation. For instance, the large US State of California has not reported in the past decade. Thus, any report on TOP epidemiology from the US is fraught with numerous assumptions and lack of any clear standardization [26-30].

The incidence of TOP is usually stated in one of three ways: total number, rate, and ratio. The TOP rate is the number of TOP procedures per 100 women aged 15 to 44 years (so-called reproductive age). The TOP ratio is the number of TOP procedures per 100 pregnancies. Pregnancy in the ratio includes live births and TOPs and it excludes spontaneous pregnancy losses and intrauterine fetal demises.

With these caveats in mind, and despite the limitation of TOP epidemiology, the utilization of TOP soared dramatically after the US Supreme Court decision. TOP numbers peaked in 1988 to 1.59 million, with the peak TOP rate in 1990 of $27.4 \mathrm{TOP} / 100$ women aged 15-44 and the peak TOP ratio in 1983 of 30.4 TOP/100 pregnancies. From 1973 to 2008, Guttmacher estimates that 50 million TOPs were performed. In 2008, US women had 1.2 M TOPs with the TOP rate being $19.6 \mathrm{TOP} / 1000$ women aged $15-44$ years $[24,25]$.

Using estimates from the Guttmacher Institute patient survey, US women in their 20 s account for $57 \%$ of all TOPs. Adolescents under 20 obtain $18 \%$ of TOP. As to race, in 2008 among women choosing TOP, $36 \%$ were non-Hispanic white, $30 \%$ were non-Hispanic black, and $25 \%$ were Hispanic. Single women (never married and not cohabitating) had $45 \%$ of TOP procedures in that year and $61 \%$ of women seeking TOP were mothers to at least one child. In terms of socioeconomic status, $42 \%$ of women seeking TOP have incomes below the US poverty level $[24,25]$. In the month they conceived, over half of the women seeking TOP were contracepting with the majority using oral contraceptives or condoms. As one might predict, inconsistent use of contraceptives in the preceding month is common $-76 \%$ of pill users and $49 \%$ of couples relying on condoms $[29,30]$.

Almost $90 \%$ of TOPs are done in the first trimester (12 weeks from the last menstrual period). Somewhere around $1 \%$ of TOPs in the US are performed after 20 weeks. These numbers have remained steady over the epoch this paper covers, although there has been a shift toward lower gestational ages with more TOPs done in the first trimester over the 40-year epoch being reviewed [26-30]. This phenomenon 
has been attributed to the approval in 2000 by the US Food and Drug Administration of mifepristone for medical TOP. Medical TOP regimens become less effective after 9 weeks and many protocols limit their use thereafter. Concurrent with widespread legalization of TOP in the US in 1973 was the introduction of vacuum aspiration (or suction curettage) which widely became the mechanism of choice for surgical TOP. This procedure can be utilized for TOP up until 13 weeks and includes cervical dilation, either chemically or mechanically, and suction to empty the uterine contents. Procedures for second trimester TOP include induction of labor chemically or mechanically, hysterotomy, hysterectomy, or dilation and evacuation (D\&E). D\&E TOP is the most common technique in the US, accounting for over $95 \%$ of the procedures done after the first trimester [31-35].

In the early 1970s, most TOP procedures were done in acute care hospitals. Over time the TOP site of service has shifted from the hospital to the outpatient setting. By 2005 , only $5 \%$ of TOPs were done in the hospital. Medical TOP approaches have allowed for procedures to shift from the medical setting to the home. Even second trimester D\&E procedures for TOP can be done in the outpatient setting [36]. Compared to other developed countries, the US TOP rate is substantially higher than Finland, Switzerland, Germany, and the Netherlands where rates range from 7 to $11 / 1000$ women and ascertainment is far better due to standard registries and record linkage capacity. Only Sweden in 2005 had a TOP rate similar to the US at 20 or so TOPs/1000 reproductive-age women. Women in European countries are more likely to undergo medical TOP than are US women [18-21].

Thus, despite expert prediction that easing TOP restrictions in the US would culminate in TOP rates less than $5 / 1000$, the utilization of TOP has been much higher than anticipated. This phenomenon has only begun to decline in the past decade despite the widespread availability and improved safety of effective contraceptives. One in ten US women will have had a TOP by the age of 20 , one in four by 30 , and one in three by 45 . Each year in the US $2 \%$ of women between 15 and 44 years of age have a TOP. This has caused experts to label TOP as the "most common of medical interventions" [28-30]. Beyond ethical and demographic concerns with widespread use of TOP in the US, it has significant epidemiologic implications. Even modest elevations in hazard ratios associated with TOP would have profound biologic effects due to its common use in the US For instance, if the hazard ratio for preterm birth associated with TOP is 1.3 , then the population attributable risk would be $3.2 \%$ and therefore over one-quarter of preterm births in developed countries would be attributable to TOP [37]. Harms or benefits associated with such a commonly used procedure, even if rather modest, would ripple through a population and have a large impact. Thus, the need for accurate incidence estimates and linkage to other health records is important to the large number of women who will have a TOP, the $75 \%$ of those having TOP who will try to have a child after TOP, and to a society interested in the health of women and children.

\section{Maternal Mortality}

As described earlier in this paper, the US TOP epidemiology is plagued by the lack of a TOP registry and reliance on what is largely survey methodology [38]. Because this system is voluntary, and also due to the inherent reluctance of surgeons to disclose serious complications such as death, underreporting is a major problem [39]. Comparing CDC Abortion Surveillance reports to deaths reported in the popular press demonstrates that, for instance in 1989, four deaths resulting from TOP did not make it into the state's statistics (the CDC reported zero deaths in that particular year) [38].

In contrast to the US, countries with mandatory reporting and the ability to link birth, abortion, and hospital registries show increased rates of mortality above US estimates and increased relative risk of death after TOP when compared to women having a child. Similar findings have been reported in the US from administrative databases, such as publiclyfunded TOPs from California [38]. This casts further doubt on contemporary US surveillance systems to generate reliable estimates for TOP-related mortality.

Unlike the identification and ascertainment of TOPrelated deaths in the US, pregnancy-related deaths are systematically sought, identified, and investigated by state maternal mortality commissions. These entities have the ability to confidentially obtain medical records, review clinician notes, and determine if a pregnancy-related death was preventable. The commissions have operated since the early 20th century. Over the past 30 years more and more US jurisdictions allow electronic linking of birth and death certificates. This automated connection process has greatly increased the number of pregnancy-related deaths identified and allowed a more thorough understanding of the epidemiology of childbirth. TOP lacks any formal registry and thus linking TOP with death is not possible [38].

TOP is a surgical procedure usually completed in minutes, whereas childbirth encompasses the 40 weeks of pregnancy and 6 weeks postpartum. Thus, TOP and its associated major complication, death, is like a single snapshot, whereas pregnancy and pregnancy-related death are like a feature length film. Moreover, any death during or 6 weeks after pregnancy is labeled pregnancy related and categorized as direct or indirect. A woman who underwent TOP in the first trimester, suffered profound depression, and four weeks later committed suicide would not be labeled a TOP-related death even if the TOP was known about. Conversely, a woman delivering at term who had a similar series of events would be labeled a pregnancy-related death. This differential window of attribution makes direct comparisons misleading.

One recent study from Chile explored 50 years of registry data from a country that prohibited TOP in 1989. Such restrictive legislation would have been predicted by many women's health epidemiologists and clinicians to greatly increase childbirth-related deaths if TOPs were truly safer. The contrary occurred with maternal mortality from pregnancy and childbirth continuing to fall even after the TOP restrictive law was passed. Increasing education levels 
of women had the most favorable impact on the falling childbirth-related maternal mortality rates [40].

TOP epidemiologists lump all deaths together across the full spectrum of gestational age despite the well-known fact that TOP morbidity and mortality increase with advancing gestational age. The fact that TOP most often occurs in the first trimester in the US skews the aggregated mortality numbers used in most comparisons toward the time in pregnancy where TOP procedures are relatively safer. The risk of death associated with TOP increases from one death for every one million TOPs at less than 9 weeks to three per one hundred thousand TOPs at 16-20 weeks to 10 per one hundred thousand at 21 or more weeks in the US [27-30].

Reardon and Coleman [41] just published an article which looked at maternal mortality for an epoch of 25 years using Danish birth and death records. Their cohort consisted of 463,473 women and they used TOP in the first pregnancy as the exposure of interest, controlling for pregnancy outcomes in subsequent gestations. For women having TOP at $<12$ weeks, cumulative mortality rates were higher from 180 days to 10 years from the index pregnancy. The association between TOP and cumulative mortality was similar but stronger for TOP $>12$ weeks gestation. The comparison group was women who delivered after 20 weeks gestation. While far from definitely answering the question, the linkage study does cast doubt on the claim that TOP is safer than pregnancy continuation.

Another problem inherent in comparing aggregated deaths for TOP and pregnancy is the failure to control for important confounders other than gestational age when the TOP is performed. Women seeking TOP in the US are younger and presumably healthier, although they are more likely to be single and of lower socioeconomic status which have negative health effects. Thus, failure to control for important confounders makes direct comparisons of crude rates even less accurate [42-46].

In terms of lives lost, current TOP epidemiologic approaches assume that the embryo or fetus has a null moral status and that the loss of a potential human being (which is the stated goal of every TOP procedure) should not be considered. This failure to account for the impact of losing a future citizen has had profound demographic consequences in countries with unrestricted access to TOP, such as the US In a horrible twist reminiscent of the eugenics movements of the 20th century, some US states have even lowered barriers to TOP with the stated intent of lowering the number of individuals needing social support or mental health services [47]. These losses are not captured in mortality statistics that solely value the life of the mother.

Despite the inherent absurdity in comparing death rates from TOP to childbirth, such comparisons continue to be done by prominent clinicians and various advocacy groups [48]. Comparisons are inherently biased and those biases may confuse women considering whether to have a TOP or continue their pregnancy. Differences in ascertainment of deaths, duration of susceptibility to mortality, lack of accounting for gestational age, and choice of appropriate comparison group make these comparisons a fool's errand.

\section{Short-Term Harms}

Like all other elective surgical or medical procedures, TOP carries the inherent risk of bleeding, infection, and damage to other organs in the genitourinary and gastrointestinal tracts. In addition, TOP procedures have unique risks of incomplete emptying of the uterus and obfuscation of the diagnosis of ectopic pregnancy [49]. As mentioned in the mortality section, the likelihood of harm is dependent on gestational age with risk directly proportional to gestational age. One US study estimates a hazard ratio of 1.38 for TOP complication for each week after a TOP procedure is performed with the same being true for TOP-related mortality [50].

Bleeding or hemorrhage (defined as estimated blood loss $>500 \mathrm{cc}$ ) occurs in up to $1 \%$ of TOPs in the first trimester and up to $2.5 \%$ of second trimester TOPs. Causes of excessive blood loss include cervical laceration, uterine perforation, atony, and retained pregnancy (products of conception). While atony may respond to uterine massage or administration of drugs that cause the uterus to contract, the other complications will require additional surgery. Rarely blood transfusion and hysterectomy will be needed [51]. Uterine perforation or puncture by the suction cannula or sharp curette during the TOP occurs in $10-15 / 1000$ procedures. Risk factors include increasing gestational age, uterine leiomyomata, and surgeon inexperience. Perforations can damage pelvic vessels, bowel, bladder, and tubes and ovaries. This complication is the most common inciting event for subsequent laparotomy or laparoscopy to inspect the pelvis for organ damage. "Silent" or unrecognized perforation with organ injury can have severe consequences [52].

Likewise, the cervix (opening to the uterus) can be torn or lacerated during a TOP. The likelihood of cervical trauma can be greatly reduced by cervical preparation with Laminaria or pharmacotherapy prior to TOP [53-55]. Up to $3 \%$ of second trimester TOP procedures are complicated by cervical trauma [56]. Unrecognized or inadequately repaired tears are one proposed mechanism for the association between TOP and preterm birth in a subsequent pregnancy. The trauma is hypothesized to culminate in cervical insufficiency.

Failure to empty the uterus completely or recognize an ectopic gestation during TOP is rare event when ultrasound is used before and after TOP procedures. One concern in the proposed scheme to increase access to TOP by having nurses performing the procedure is their lack of familiarity with diagnostic imaging. These TOP complications when not recognized or attended to can have deleterious health outcomes, including death.

Infection is the most common short-term complication after TOP [51]. It occurs after 1 to $5 \%$ of surgical TOPs and is usually polymicrobial in nature [57]. Antibiotic prophylaxis can reduce this risk in surgical TOP. The so-called septic abortion is the most common presentation and usually responds to broad spectrum antibiotics and evacuation of any retained portions of the pregnancy. Rarely, laparotomy will be needed to drain an abscess or remove an infected uterus. There has been a recent cluster of fatal toxic shock after medical TOP caused by Clostridium species. The epidemiology of this complication and role of microbiotic prophylaxis 
remains to be elucidated $[56,57]$. When medical and surgical TOP procedures are directly compared, more women in the medical TOP groups will require surgical evacuation and experience more bleeding, while surgical TOP has more traumatic complications [58-60].

\section{Long-Term Harms}

While there are numerous claims made asserting that TOP has no long-term consequences beyond the immediate complications described above, careful readers will be struck by the paucity of data on this topic, particularly from the US Moreover, as mentioned throughout this paper, all data are observational rather than experimental. Case-control studies are particularly prone to differential reporting of TOP exposure and a serious illness such as a new cancer diagnosis may make a case more forthcoming about a TOP than would be a control of this sensitive issue. In the US, lack of TOP registration and thus inability to conduct cohort studies in which there is no linkage to birth certificates or cancer registries makes all investigators reliant on self-reports of TOP exposure [61].

TOP does not appear to be associated with subsequent increased risk of subfertility, spontaneous abortion, or ectopic pregnancy. There has been shown a consistent, modest association between TOP and placenta previa in a subsequent pregnancy.

I will not belabor those findings, but turn to three conditions in which the literature is more comprehensive in reporting links between TOP and the health outcome in question. Those will include preterm birth, breast cancer, and mental health problems. Each is an important women's health outcome with lifetime prevalence greater than $10 \%$. Readers should harken back to the discussion about population attributable risk to refresh their memories that even small increases in risk can have profound health consequences given the fact that one out of three US women will undergo TOP in their reproductive years.

Preterm birth (PTB) prior to 37 weeks gestation is the most common cause of infant death and disability in the US and complicates more than one in ten births [62]. The etiology remains unclear, and concurrent with the social experiment of abolishing legal restrictions to TOP in the US initiated by the Roe versus Wade decision, the US has experienced an ever-increasing rate of PTB. Other changes have occurred over that epoch such as increased use of subfertility treatment, which increases the risk of multifetal gestations and preterm birth. Mechanical trauma to the cervix, infection, and scarring of the endometrium are all putative mechanisms for how TOP could increase the likelihood of PTB [63].

In 2009, Shah and Zao, on behalf of the "Knowledge Synthesis Group of Determinants of Preterm/Low Birth Weight" conducted a rigorous, systematic meta-analysis [37]. The world's literature was independently reviewed and 37 studies were assimilated. One TOP was associated with increased odds of PTB (OR-1.36, 95\% CI 1.24-1.50) and more than one TOP with increased odds of PTB (OR-1.93, 95\% CI
1.28-2.71). Moderate statistical heterogeneity was identified between studies and the results persisted after adjustment for known confounders. The population attribute risk was $2.7 \%$ and thus up to one-third of PTBs in contemporary perinatal practice in the US could be due to TOP [64]. There are over 130 published studies showing an association between TOP and either preterm birth or its surrogate, low birthweight [65196].

In one of the larger and most comprehensive studies published to date, Klemetti et al. recently reported that in first-time mothers, TOP was associated with preterm birth, particularly "very early" preterm births at $<28$ weeks gestation. Using the Finnish Medical Birth and Abortion Registries to link 300,858 records, they not only showed an association between TOP in a first pregnancy and very early preterm birth, but also showed a "dose response" effect with more TOPs increasing the strength of the association. They call for health care professionals and the public to be warned about the risks [197].

This phenomenon is of great importance in perinatal epidemiology. Most risk factors for PTB, such as race or multifetal gestation, are not modifiable, while TOP is mutable $[62,63]$. In my clinical experience, subsequent pregnancy performance is of paramount importance to a woman facing a crisis or unintended pregnancy. Up to $75 \%$ of US women opting for TOP will have a subsequent pregnancy, so the importance of the finding from public health, demographic, and informed consent perspectives should not be underestimated.

Studies exploring an association between TOP and breast cancer have had mixed results with some showing small increases in risk and others demonstrating no difference between exposed and unexposed women. The single metaanalysis found a summary odds ratio of 1.3 (95\% CI 1.2-1.4) [62] while a US National Cancer Institute review found no effect [198], as did the Collaborative Group on Hormonal Factors in Breast Cancer in a reanalysis of 53 studies [199]. In 2002, our research group presented a novel theory based on the Gail Model, which is widely used by clinicians to predict 5 -year and lifetime risk of breast cancer, and has been used as the entry criteria for chemoprevention studies. In this model, a term birth and lactation are protective, reducing future risk, and thus we speculated that a woman choosing TOP and foregoing childbirth would experience a loss of protection. This would be of no mere consequence for younger women as the younger a woman is with her first term pregnancy, the greater protective effect she might enjoy. To our knowledge no one has gathered prospective data to test our hypothesis. This link, or lack thereof, remains a field ripe for further exploration [61].

The story is almost identical to breast cancer for TOP and mental health. Individual studies are mixed, albeit numerous, indicating harm [198, 200-300]. One meta-analysis shows a modest increased risk of mood disorders, suicide, and substance abuse in women having TOP [301], and two reviews by national organizations have concluded that the data are limited and no firm conclusions can be drawn [302]. Problems include what will begin to sound like a familiar litany to readers of this paper-the limits of observational 
data, lack of US registry data, recall bias, and the list goes on [303]. Again, this is an area that merits investigators' attention, as the population attributable risk for the metaanalysis was that up to $10 \%$ of mental health problems, in women who experience a disproportionate share of mental health problems, can be linked to TOP.

\section{Clinicians Providing Top}

In the US after Roe versus Wade in 1973, there was an increase in the number of TOP providers up until 1982. After 1982, the number has steadily declined and by 2005 the total was close to the number in 1973. Coincidental with this decline has been a shift in service location from the inpatient to the outpatient setting, where over two-thirds of TOP procedures in the US in 2005 were performed. Only $23 \%$ of TOP providers offer procedures after 20 weeks and only $11 \%$ after 24 weeks. TOP seems to be preferentially done in urban setting with $87 \%$ of US counties lacking a TOP provider [304].

In response to a decline in the number of US OBG residents opting to not learn how to perform TOPs, and the subsequent decline in TOP providers, a privately-funded initiative was started in 1999 to try to reverse this trend. Over 40 US residencies have affiliated with the program. The program is named after Kenneth Ryan, who was the longstanding OBG Chair at Harvard and an advocate of legal TOP. Whether training is "routine" or "optional" remains a source of much discussion [305-307]. Federal funding of graduate medical education in the US provides residents with some protection on conscience and the freedom to choose whether to participate in TOP or not. It remains to be seen how the Affordable Care Act will impact conscience and resident decision-making about participation in TOP.

\section{Law, Policy, and the Judiciary}

TOP is a contentious issue in US politics and culture and is a theme of both state and federal executive and legislative campaigns. Some of the contention is no doubt due to the fact that in 1973 the US Supreme Court in Roe versus Wade and Doe versus Bolton decreed an unrestricted right to TOP within the privacy provisions of the US Constitution. That decision overrode local restrictions in all states and territories and shifted the grounds for settling disputes on TOP from the legislative branch to the judiciary. Moreover, the decision overstepped cultural and religious prohibitions founded on the premise that fetus or embryos are at least potential individuals deserving moral status and societal protection [308].

The 1973 decision did not find the right to TOP to be absolute, but did extend to that decision the highest degrees of constitutional protection, so-called strict scrutiny. Under the doctrine of strict scrutiny no state can restrict TOP unless there is a compelling state interest. The majority opinion found no state interest that would allow restrictions in the first trimester, only the health of the woman could be used to restrict TOP in the second trimester, and TOP in the third trimester (after viability) could be restricted except in situations where a woman's life or health was threatened. Health was broadly defined in the two decisions to include mental and emotional health.

Since 1973, the US Supreme Court has explicitly declined to overturn its decision on TOP. Despite that hesitancy, beginning in 1989 and with subsequent rulings, the Supreme Court has diminished the constitutional protection of the right for TOP and essentially degraded the standard of "strict scrutiny" that was originally assigned. The fruit of that change has been various state statutes requiring things such as a proscribed waiting period, mandatory informed consent, parental involvement for minors seeking TOP, and data reporting requirements. In 2007, the US Supreme Court went even further in Gonzales versus Carhart which upheld the "Partial Birth Abortion Ban Act of 2003." That opinion allowed states to prohibit certain TOP techniques and for the first time there were no exceptions allowed for the health of the mother $[309,310]$.

With the gradual relaxation of strict scrutiny, state legislatures and Congress began to regulate TOP in the US In 1976, the Hyde Amendment prohibited use of federal funds to pay for TOP procedures. States followed suit to forbid the use of state dollars (32 states and the District of Columbia) for TOP and to regulate insurance coverage for both public and private employees. Other restrictions include licensing and inspection requirements for TOP facilities, prohibition of certain procedures, mandatory information and waiting periods, required parental involvement, conscience clauses for both clinicians and institutions, and limitation of graduate medical education training requirements. Mandated ultrasounds prior to TOP with patients giving the option to view the images is the latest area where new state laws are trying to regulate TOP practices. TOP was a major issue in passage of the Affordable Care Act and how those laws will affect TOP funding and training for individuals and institutions await the Act's implementation [306]. Powerful public interest groups have risen on both sides of the restriction issue and are often on opposite sides of lawsuits to overturn new laws [310].

\section{Conclusion}

The natural experiment in abolishing most restrictions on TOP initiated by the US Supreme Court in 1973 has proven the fallacies inherent in expert predictions. First, uptake of this procedure by women was far greater than predicted and in 2012 one out of three women in the US will have a TOP by the age of $45[310,311]$. Second, a myopic focus on short-term complications has documented, albeit incompletely, the relative safety of the procedure at early gestational ages, but failed to adequately explore the long term health consequences. This is of particular importance with such widespread uptake of TOP where even modest increases in hazard ratios can have a huge impact on a population's health. The example of PTB stated herein is illustrative of this impact. The health impact of TOP is further befuddled by a paucity of reliable epidemiologic data on TOP and 
an inability to reliably know how often TOP is performed in the US and link administrative databases. Putting aside for a moment ethical considerations on the moral status of the embryo or fetus versus the status of his or her mother (which science is inadequate to address), there is a vacuum in TOP epidemiology and a real need to improve and upgrade our sources of observational data. Respect for maternal autonomy and the difficult decisions a woman faces in an unintended or crisis pregnancy must be considered cry out for nothing less.

\section{References}

[1] M. Hout, "Abortion politics in the United States, 1972-1994: from single issue to ideology," Gender Issues, vol. 17, no. 2, pp. 3-34, 1999.

[2] D. R. Mcfarlane, "U.S. abortion policy since Roe versus Wade," The American Journal of Gynecologic Health, vol. 7, no. 4, pp. 98-106, 1993.

[3] J. Rovner, "25 years later, US abortion war still drags on," The Lancet, vol. 351, no. 9099, p. 348, 1998.

[4] B. Weiss, "Roe versus Wade at 25: the tough questions linger," Medical Economics, vol. 75, no. 15, pp. 138-148, 1998.

[5] S. A. Cohen, "25 years after Roe: new technological parameters for an old debate," The Guttmacher Report on Public Policy, vol. 1, no. 1, pp. 5-12, 1998.

[6] Catholic Church and United States Conference of Catholic Bishops, "A matter for the heart: the 30th anniversary of Roe versus Wade," Origins, vol. 32, no. 24, pp. 398-399, 2002.

[7] W. Cates Jr., D. A. Grimes, and K. F. Schulz, "The public health impact of legal abortion: 30 years later," Perspectives on Sexual and Reproductive Health, vol. 35, no. 1, pp. 25-28, 2003.

[8] D. A. Grimes and G. Stuart, "Abortion jabberwocky: the need for better terminology," Contraception, vol. 81, no. 2, pp. 93-96, 2010.

[9] J. M. Thorp, 'O', evidence-based medicine-where is your effectiveness?" BJOG: An International Journal of Obstetrics and Gynaecology, vol. 114, no. 1, pp. 1-2, 2007.

[10] R. K. Jones and K. Kooistra, "Abortion incidence and access to services in the United States, 2008," Perspectives on Sexual and Reproductive Health, vol. 43, no. 1, pp. 41-50, 2011.

[11] R. K. Jones and M. L. Kavanaugh, "Changes in abortion rates between 2000 and 2008 and lifetime incidence of abortion," Obstetrics and Gynecology, vol. 117, no. 6, pp. 1358-1366, 2011.

[12] A. Templeton and D. A. Grimes, "Clinical practice. A request for abortion," The New England Journal of Medicine, vol. 365, no. 23, pp. 2198-2204, 2011.

[13] J. A. Martin, B. E. Hamilton, S. J. Ventura et al., "Births: final data for 2009," National Vital Statistics Reports, vol. 60, no. 1, pp. 1-70, 2011.

[14] T. R. Raine, "Pregnancy termination. Foreword," Clinical Obstetrics and Gynecology, vol. 52, no. 2, pp. 115-118, 2009.

[15] R. K. Jones and L. B. Finer, "Who has second-trimester abortions in the United States?" Contraception, vol. 85, no. 6, pp. 544-551, 2012.

[16] L. Say, R. Kulier, M. Gülmezoglu, and A. Campana, "Medical versus surgical methods for first trimester termination of pregnancy," Cochrane Database of Systematic Reviews, no. 1, Article ID CD003037, 2005.

[17] R. Kulier, A. M. Gülmezoglu, G. J. Hofmeyr, L. N. Cheng, and A. Campana, "Medical methods for first trimester abortion,"
Cochrane Database of Systematic Reviews, no. 1, Article ID CD002855, 2004.

[18] G. Sedgh, S. Singh, I. H. Shah, E. Ahman, S. K. Henshaw, and A. Bankole, "Induced abortion: incidence and trends worldwide from 1995 to 2008," The Lancet, vol. 379, no. 9816, pp. 625-632, 2012.

[19] G. Sedgh, S. Singh, S. K. Henshaw, and A. Bankole, "Legal abortion worldwide in 2008: levels and recent trends," Perspectives on Sexual and Reproductive Health, vol. 43, no. 3, pp. 188-198, 2011.

[20] G. Sedgh, S. K. Henshaw, S. Singh, A. Bankole, and J. Drescher, "Legal abortion worldwide: incidence and recent trends," International Family Planning Perspectives, vol. 33, no. 3, pp. 106-116, 2007.

[21] G. Sedgh, S. K. Henshaw, S. Singh, A. Bankole, and J. Drescher, "Legal abortion worldwide: incidence and recent trends," Perspectives on Sexual and Reproductive Health, vol. 39, no. 4, pp. 216-225, 2007.

[22] S. K. Henshaw, S. Singh, and T. Haas, "The incidence of abortion worldwide," International Family Planning Perspectives, vol. 25, supplement, pp. S30-S38, 1999.

[23] D. A. Grimes, "Epidemiologic research using administrative databases: garbage in, garbage out," Obstetrics and Gynecology, vol. 116, no. 5, pp. 1018-1019, 2010.

[24] R. K. Jones and K. Kooistra, "Abortion incidence and access to services in the United States, 2008," Perspectives on Sexual and Reproductive Health, vol. 43, no. 1, pp. 41-50, 2011.

[25] R. K. Jones, K. Kost, S. Singh, S. K. Henshaw, and L. B. Finer, "Trends in abortion in the United States," Clinical Obstetrics and Gynecology, vol. 52, no. 2, pp. 119-129, 2009.

[26] W. Cates, D. A. Grimes, and K. F. Schulz, "Abortion surveillance at CDC. Creating public health light out of political heat," American Journal of Preventive Medicine, vol. 19, no. 1, supplement, pp. 12-17, 2000.

[27] K. Pazol, A. A. Creanga, and S. B. Zane, "Trends in use of medical abortion in the United States: reanalysis of surveillance data from the centers for disease control and prevention, 2001-2008," Contraception, vol. 86, no. 6, pp. 746-751, 2012.

[28] K. Pazol, S. B. Zane, W. Y. Parker et al., "Abortion surveillanceUnited States, 2008," MMWR Surveillance Summaries, vol. 60, no. 15, pp. 1-41, 2011.

[29] K. Pazol, S. B. Zane, W. Y. Parker et al., "Abortion surveillance-United states, 2007," Morbidity and Mortality Weekly Report, vol. 60, no. 1, pp. 1-39, 2011.

[30] K. Pazol, S. Zane, W. Y. Parker et al., "Erratum: abortion surveillance-United States, 2007," MMWR Surveillance Summaries, vol. 60, no. 10, p. 315, 2011.

[31] R. K. Jones, J. E. Darroch, and S. K. Henshaw, "Contraceptive use among U.S. women having abortions in 2000-2001," Perspectives on Sexual and Reproductive Health, vol. 34, no. 6, pp. 294-303, 2002.

[32] R. K. Jones and L. B. Finer, "Who has second-trimester abortions in the United States?" Contraception, vol. 85, no. 6, pp. 544-551, 2012.

[33] J. Kerns, R. Vanjani, L. Freedman, K. Meckstroth, E. A. Drey, and J. Steinauer, "Women's decision making regarding choice of second trimester termination method for pregnancy complications," International Journal of Gynecology and Obstetrics, vol. 116, no. 3, pp. 244-248, 2012.

[34] K. A. Whitley, K. Trinchere, W. Prutsman, J. N. Quiñones, and M. L. Rochon, "Midtrimester dilation and evacuation 
versus prostaglandin induction: a comparison of composite outcomes," American Journal of Obstetrics and Gynecology, vol. 205, no. 4, pp. 386.e1-386.e7, 2011.

[35] L. Borgatta, N. Kapp, and Society of Family Planning, "Clinical guidelines. Labor induction abortion in the second trimester," Contraception, vol. 84, no. 1, pp. 4-18, 2011.

[36] A. Rolnick and S. Vorhies, "Legal restrictions and complications of abortion: insighs from data on complication rates in the United States," Jurnal of Public Health Policy, vol. 33, pp. 348-362, 2012.

[37] P. S. Shah and J. Zao, "Induced termination of pregnancy and low birthweight and preterm birth: a systematic review and meta-analyses," BJOG: An International Journal of Obstetrics and Gynaecology, vol. 116, no. 11, pp. 1425-1442, 2009.

[38] D. C. Reardon, T. W. Strahan, J. M. Thorp Jr., and M. W. Shuping, "Deaths associated with abortion compared to childbirth - a review of new and old data and the medical and legal implications," The Journal of Contemporary Health Law and Policy, vol. 20, no. 2, pp. 279-327, 2004.

[39] H. W. Lawson, A. Frye, H. K. Atrash, J. C. Smith, H. B. Shulman, and M. Ramick, "Abortion mortality, United States, 1972 through 1987," American Journal of Obstetrics and Gynecology, vol. 171, no. 5, pp. 1365-1372, 1994.

[40] E. Koch, J. Thorp, M. Bravo et al., "Women's education level, maternal health facilities, abortion legislation and maternal deaths: a natural experiment in Chile from 1957 to 2007," PLoS ONE, vol. 7, no. 5, Article ID e36613, 2012.

[41] D. C. Reardon and P. K. Coleman, "Short and long term mortality rates associated with first pregnancy outcome: population register based study for Denmark 1980-2004," Medical Science Monitor, vol. 18, no. 9, pp. PH71-PH76, 2012.

[42] J. M. Belizán, P. Buekens, F. Althabe, and E. Bergel, "Maternal survival: more research is needed," The Lancet, vol. 368, no. 9553, pp. 2123-2124, 2006.

[43] C. Deneux-Tharaux, C. Berg, M. H. Bouvier-Colle et al., "Underreporting of pregnancy-related mortality in the United States and Europe," Obstetrics and Gynecology, vol. 106, no. 4, pp. 684-692, 2005.

[44] C. Deneux-Tharaux, C. Berg, M. H. Bouvier-Colle et al., "Erratum: underreporting of pregnancy-relatedmortality in the United States and Europe," Obstetrics and Gynecology, vol. 107, no. 1, p. 209, 2006.

[45] M. Gissler, C. Deneux-Tharaux, S. Alexander et al., "Pregnancyrelated deaths in four regions of Europe and the United States in 1999-2000: characterisation of unreported deaths," European Journal of Obstetrics Gynecology and Reproductive Biology, vol. 133, no. 2, pp. 179-185, 2007.

[46] A. A. Creanga, C. J. Berg, C. Syverson, K. Seed, F. C. Bruce, and W. M. Callaghan, "Race, ethnicity, and nativity differentials in pregnancy-related mortality in the United States: 1993-2006," Obstetrics and Gynecology, vol. 120, no. 2, part 1, pp. 261-268, 2012.

[47] J. Schoen, Choice \& Coercion. Introduction: A Great Thing for Poor Folks, The University of North Carolina Press, Chapel Hill, NC, USA, 2005.

[48] E. G. Raymond and D. A. Grimes, "The comparative safety of legal induced abortion and childbirth in the United States," Obstetrics and Gynecology, vol. 119, no. 2, part 1, pp. 215-219, 2012.

[49] L. M. Keder, "Best practices in surgical abortion," American Journal of Obstetrics and Gynecology, vol. 189, no. 2, pp. 418-422, 2003.
[50] J. Diedrich and J. Steinauer, "Complications of surgical abortion," Clinical Obstetrics and Gynecology, vol. 52, no. 2, pp. 205-212, 2009.

[51] G. M. Flett and A. Templeton, "Surgical abortion," Best Practice and Research Clinical Obstetrics and Gynaecology, vol. 16, no. 2, pp. 247-261, 2002.

[52] R. Goldchmit, Y. Zalel, U. Elchalal, A. Matzkel, and R. Dgani, "Management of uterine perforation complicating firsttrimester termination of pregnancy," Israel Journal of Medical Sciences, vol. 31, no. 4, pp. 232-234, 1995.

[53] J. L. Hayes and M. C. Fox, "Cervical dilation in second-trimester abortion," Clinical Obstetrics and Gynecology, vol. 52, no. 2, pp. 171-178, 2009.

[54] V. Berghella, J. Airoldi, A. O’Neill, K. Einhorn, and M. Hoffman, "Misoprostol for second trimester pregnancy termination in women with prior caesarean: a systematic review," BJOG: An International Journal of Obstetrics and Gynaecology, vol. 116, no. 9, pp. 1151-1157, 2009.

[55] D. Grossman, K. Blanchard, and P. Blumenthal, "Complications after second trimester surgical and medical abortion," Reproductive Health Matters, vol. 16, no. 31, supplement, pp. 173-182, 2008.

[56] C. Shannon, L. P. Brothers, N. M. Philip, and B. Winikoff, "Infection after medical abortion: a review of the literature," Contraception, vol. 70, no. 3, pp. 183-190, 2004.

[57] L. Rahangdale, "Infectious complications of pregnancy termination," Clinical Obstetrics and Gynecology, vol. 52, no. 2, pp. 198-204, 2009.

[58] L. Say, R. Kulier, M. Gülmezoglu, and A. Campana, "Medical versus surgical methods for first trimester termination of pregnancy," Cochrane Database of Systematic Reviews, no. 1, Article ID CD003037, 2005.

[59] A. Lipp, "A review of developments in medical termination of pregnancy," Journal of Clinical Nursing, vol. 17, no. 11, pp. 1411-1418, 2008.

[60] P. A. Lohr, J. L. Hayes, and K. Gemzell-Danielsson, "Surgical versus medical methods for second trimester induced abortion," Cochrane Database of Systematic Reviews, no. 1, Article ID CD006714, 2008.

[61] J. M. Thorp Jr., K. E. Hartmann, and E. Shadigian, "Long-term physical and psychological health consequences of induced abortion: review of the evidence," Obstetrical and Gynecological Survey, vol. 58, no. 1, pp. 67-79, 2003.

[62] R. L. Goldenberg, J. F. Culhane, J. D. Iams, and R. Romero, "Epidemiology and causes of preterm birth," The Lancet, vol. 371, no. 9606, pp. 75-84, 2008.

[63] C. V. Ananth and A. M. Vintzileos, "Epidemiology of preterm birth and its clinical subtypes," Journal of Maternal-Fetal and Neonatal Medicine, vol. 19, no. 12, pp. 773-782, 2006.

[64] R. Freak-Poli, A. Chan, G. Tucker, and J. Street, "Previous abortion and risk of pre-term birth: a population study," Journal of Maternal-Fetal and Neonatal Medicine, vol. 22, no. 1, pp. 1-7, 2009.

[65] G. Barsy and J. Sarkany, "Impact of induced abortion on the birth rate and infant mortality," Demografia, vol. 6, pp. 427-467, 1963.

[66] K. Miltenyi, "On the effects of induced abortion," Demografia, vol. 7, pp. 73-87, 1964.

[67] Y. Furusawa and Y. Koya, "The Influence of artificial abortion on deliveryHarmful effects of induced abortion," Y. Koya, Ed., pp. 74-83, Family Planning Federation of Japan, Tokyo, Japan, 1966. 
[68] A. Arvay, M. Gorgey, and L. Kapu, "La relation entre les avortements (interruptions de la grossesse) et les accouchements prematures," Revue Française de Gynécologie et d'Obstétrique, vol. 62, pp. 81-86, 1967.

[69] P. Drac and Z. Nekvasilova, "Premature termination of pregnancy after previous interruption of pregnancy," Ceská Gynekologie, vol. 35, pp. 332-333, 1970.

[70] A. Dolezal, V. Andrasova, S. Tittlbachova et al., "Interruption of pregnancy and their relation to premature labous and hyptrophic foetuses," Ceská Gynekologie, vol. 36, p. 331, 1970.

[71] S. N. Pantelakis, G. C. Papadimitriou, and S. A. Doxiadis, "Influence of induced and spontaneous abortions on the outcome of subsequent pregnancies," American Journal of Obstetrics and Gynecology, vol. 116, no. 6, pp. 799-805, 1973.

[72] J. W. van der Slikke and P. E. Treffers, "Influence of induced abortion on gestational duration in subsequent pregnancies," British Medical Journal, vol. 1, no. 6108, pp. 270-272, 1978.

[73] J. A. Richardson and G. Dixon, "Effects of legal termination on subsequent pregnancy," British Medical Journal, vol. 1, no. 6021, pp. 1303-1304, 1976.

[74] G. Papaevangelou, A. S. Vrettos, C. Papadatos, and D. Alexiou, "The effect of spontaneous and induced abortion on prematurity and birthweight," The Journal of Obstetrics and Gynaecology of the British Commonwealth, vol. 80, no. 5, pp. 410-422, 1973.

[75] Z. Bognar and A. Czeizel, "Mortality and morbidity associated with legal abortion in Hungary, 1960-1973," American Journal of Public Health, vol. 66, no. 6, pp. 568-575, 1976.

[76] B. Grindel, H. Lubinski, and M. Voigt, "Induced abortion in primigravidae and subsequent pregnancy, with particular consideration of low birth weight," Zentralblatt fur Gynakologie, vol. 101, no. 16, pp. 1009-1014, 1979.

[77] E. Obel, "Pregnancy complications following legally induced abortion with special reference to abortion technique," Acta Obstetricia et Gynecologica Scandinavica, vol. 58, no. 2, pp. 147-152, 1979.

[78] World Health Organization Task Force on the Sequelae of Abortion, "Gestation, birthweight and spontaneous abortion," The Lancet, vol. 1, no. 8108, pp. 142-145, 1979.

[79] G. J. Ratten and N. A. Beischer, "The effect of termination of pregnancy on maturation of subsequent pregnancy," Medical Journal of Australia, vol. 1, no. 11, pp. 479-480, 1979.

[80] L. H. Roht, H. Aoyama, G. E. Leinen, and P. W. Callen, "The association of multiple induced abortions with subsequent prematurity and spontaneous abortion," Acta Obstetrica et Gynaecologica Japonica, vol. 23, no. 2, pp. 140-145, 1976.

[81] S. Harlap and A. M. Davies, "Late sequelae of induced abortion: complications and outcome of pregnancy and labor," American Journal of Epidemiology, vol. 102, no. 3, pp. 217-224, 1975.

[82] O. Koller and S. N. Eikhom, "Late sequelae of induced abortion in primigravidae. The outcome of the subsequent pregnancies," Acta Obstetricia et Gynecologica Scandinavica, vol. 56, no. 4, pp. 311-317, 1977.

[83] T. H. Lean, C. J. R. Hogue, and J. Wood, "Low birth weight after induced abortion in Singapore," in Proceedings of the 105th Annual Meeting of the American Public Health Association, Washington, DC, USA, October 1977.

[84] World Health Organization, Special Programme of Research, Development and Research Training in Human Reproduction: Seventh Annual Report, World Health Organization, Geneva, Switzerland, 1978.
[85] Hungarian Central Statistical Office, The Effect of the Number of Abortions on Premature Births and Perinatal Mortality in Hungary, Budapest, Hungary, 1972.

[86] A. Czeizel, Z. Bognár, G. Tusnády, and P. Révész, “Changes in mean birth weight and proportion of low-weight births in Hungary," British Journal of Preventive and Social Medicine, vol. 24, no. 3, pp. 146-153, 1970.

[87] W. Dziewulska, "Abortion in the past and the fate of a subsequent pregnancy. II. State of the newborn," Ginekologia Polska, vol. 44, no. 10, pp. 1143-1148, 1973.

[88] M. Kaminski, J. Goujard, and C. Rumeau-rouquette, "Prediction of low birthweight and prematurity by a multiple regression analysis with maternal characteristics known since the beginning of the pregnancy," International Journal of Epidemiology, vol. 2, no. 2, pp. 195-204, 1973.

[89] J. Chabada, A. Pontuch, I. Sutta, and G. Pohlová, "Interruption of gravidity as a cause of premature labour," Ceská Gynekologie, vol. 39, no. 5, pp. 329-330, 1974.

[90] J. Fedrick, "Antenatal identification of women at high risk of spontaneous pre-term birth," British Journal of Obstetrics and Gynaecology, vol. 83, no. 5, pp. 351-354, 1976.

[91] O. Pohanka, B. Balogh, and M. Rutkovszky, "The impact of abortion on the birth weight of newborns," Orvosi Hetilap, vol. 116, pp. 1983-1989, 1975.

[92] M. Mikolas, "The effect of the legalization of abortion on public health and some of its social concomitants in Hungary," Demografia, vol. 16, pp. 70-113, 1973.

[93] M. Link and A. Wichmann, "Pregnancy in adolescents," Zentralblatt fur Gynakologie, vol. 98, no. 11, pp. 682-689, 1976.

[94] P. Knarre, "Influence of abortions and interruptions of pregnancy in subsequent deliveries. II cause of labor," Zentralblatt fur Gynakologie, vol. 98, no. 10, pp. 591-594, 1976.

[95] H. Kreiblich and E. Ehring, "Effect of abortion on subsequent fertility with special reference to the abortion process," Zentralblatt Fur Gynakologie, vol. 100, no. 19, pp. 1254-1260, 1978.

[96] F. Macku, V. Rokytova, and O. Titmann, "Artificial interruption of pregnancy in primigravidae as a risk factor in future pregnancies," Ceská Gynekologie, vol. 43, no. 5, pp. 340-343, 1978.

[97] C. Zwahr, M. Voigt, L. Kunz, F. Thielemann, and H. Lubinski, "Multidimensional investigations to elucidate relationships between case histories of interruption of pregnancy and premature deliveries and low birth weight," Zentralblatt fur Gynakologie, vol. 101, no. 23, pp. 1502-1509, 1979.

[98] S. von Lembrych, "Schwangerschafts-Geburts-und Wochenbett verlauf nach kunsticher Unterbrechung der ersten Graviditat," ZentrablGenaecol, vol. 94, p. 164, 1972.

[99] C. Zwahr, M. Voigt, L. Kunz, F. Thielemann, and H. Lubinski, "Relationships between interruption, abortion, and premature birth and low birth weight," Zentralblatt fur Gynakologie, vol. 102, no. 13, pp. 738-747, 1980.

[100] H. Kreibich and A. Ludwig, "Early and late complications of induced abortion in young primigravidae (with recommendations on measures to be taken)," Zeitschrift fur Arztliche Fortbildung, vol. 74, no. 7, pp. 311-316, 1980.

[101] A. Levin, S. Schoenbaum, R. Monson, P. Stubblefield, and K. Ryan, "Association of induced abortion with subsequent pregnancy loss," The Journal of the American Medical Association, vol. 243, no. 24, pp. 2495-2499, 1980.

[102] V. Legrillo, P. Quickenton, G. D. Therriault et al., "Effect of induced abortion on subsequent reproductive function," Final report to NICHD, State Health Department, Albany, NY, USA, 1980. 
[103] E. B. Obel, "Long-term sequelae following legally induced abortion," Danish Medical Bulletin, vol. 27, no. 2, pp. 61-74, 1980.

[104] P. E. Slater, A. M. Davies, and S. Harlap, "The effect of abortion method on the outcome of subsequent pregnancy," Journal of Reproductive Medicine for the Obstetrician and Gynecologist, vol. 26, no. 3, pp. 123-128, 1981.

[105] R. C. Lerner and A. O. Varma, "Prospective study of the outcome of pregnancy subsequent to previous induced abortion," Final Report, Contract no (N01-HD-62803), Downstate Medical Center, SUNY, Brooklyn, NY, USA, 1981.

[106] G. S. Berkowitz, "An epidemiologic study of preterm delivery," American Journal of Epidemiology, vol. 113, no. 1, pp. 81-92, 1981.

[107] I. Lampe Lg Batar, R. P. Bernard, E. M. Kendall, and K. G. Manton, "Effects of smoking and of induced abortion on pregnancy outcome," IPPF Medical Bulletin, vol. 15, no. 2, p. 3, 1981.

[108] C. Madore, W. E. Hawes, F. Many, and A. C. Hexter, "A study on the effects of induced abortion on subsequent pregnancy outcome," American Journal of Obstetrics and Gynecology, vol. 139, no. 5, pp. 516-521, 1981.

[109] S. Linn, S. C. Schoenbaum, R. R. Monson et al., "No association between coffee consumption and adverse outcomes of pregnancy," The New England Journal of Medicine, vol. 306, no. 3, pp. 141-145, 1982.

[110] N. M. Pompe-Tansek, L. Andolsek, and B. Tekovcic, “The effect of artificial abortion on the course and result of subsequent pregnancy," Jugoslavenska Ginekologija i Opstetricija, vol. 22, no. 5-6, pp. 118-120, 1982.

[111] J. I. Puyenbroek and L. A. M. Stolte, “The relationship between spontaneous and induced abortion and the occurrence of second-trimester abortion in subsequent pregnancies," European Journal of Obstetrics Gynecology and Reproductive Biology, vol. 14, no. 5, pp. 299-309, 1983.

[112] C. Zwahr and M. Voigt, "The effect of various parameters on the incidence of premature births," Zentralblatt fur Gynakologie, vol. 105, pp. 1307-1312, 1983.

[113] D. Schuler and A. Klinger, "Causes of low birthweight in Hungary," Acta Paediatrica Hungarica, vol. 25, no. 1-2, pp. 173-185, 1984.

[114] R. M. Pickering and J. F. Forbes, "Risks of preterm delivery and small-for-gestational age infants following abortion: a population study," British Journal of Obstetrics and Gynaecology, vol. 92, no. 11, pp. 1106-1112, 1985.

[115] J. Lumley, "Very low birth-weight $(<1,500 \mathrm{~g})$ and previous induced abortion: Victoria 1982-1983," Australian and New Zealand Journal of Obstetrics and Gynaecology, vol. 26, no. 4, pp. 268-272, 1986.

[116] P. H. Shiono and M. A. Klebanoff, "Ethnic differences in preterm and very preterm delivery," American Journal of Public Health, vol. 76, no. 11, pp. 1317-1321, 1986.

[117] A. Peterlin and L. Andolsek, "The effect of induced abortion in adolescence on the manifestations of spontaneous abortion, premature labor and birth weight," Jugoslavenska Ginekologija $i$ Perinatologija, vol. 26, no. 3-4, pp. 49-52, 1986.

[118] M. G. Ross, C. J. Hobel, J. R. Bragenier, M. B. Bear, and R. L. Bemis, "A simplified risk-scoring system for prematurity," American Journal of Perinatology, vol. 3, no. 4, pp. 339-344, 1986.
[119] E. Lieberman, K. J. Ryan, R. R. Monson, and S. C. Schoenbaum, "Risk factors accounting for racial differences in the rate of premature birth," The New England Journal of Medicine, vol. 317, no. 12, pp. 743-748, 1987.

[120] G. Krasomski, A. Gładysiak, and J. Krajewski, "Fate of subsequent pregnancies after induced abortion in primiparae," Wiadomosci Lekarskie, vol. 40, no. 23, pp. 1593-1595, 1987.

[121] D. M. Main, D. Richardson, S. G. Gabbe, S. Strong, and S. C. Weller, "Prospective evaluation of a risk scoring system for predicting preterm delivery in black inner city women," Obstetrics and Gynecology, vol. 69, no. 1, pp. 61-66, 1987.

[122] D. S. Seidman, P. Ever-Hadani, P. E. Slater, S. Harlap, D. K. Stevenson, and R. Gale, "Child-bearing after induced abortion: reassessment of risk," Journal of Epidemiology and Community Health, vol. 42, no. 3, pp. 294-298, 1988.

[123] C. Zwahr, D. Neubert, U. Triebel, M. Voight, and K. H. Kruppel, "Correlation between some environmental, anamnestic and social markers of pregnant patients and the delivery of autotrophic premature and hypotrophic newborn infants," Zentralblatt fur Gynakologie, vol. 110, pp. 479-487, 1988.

[124] E. Mueller-Heubach and D. S. Guzick, "Evaluation of risk scoring in a preterm birth prevention study of indigent patients," American Journal of Obstetrics and Gynecology, vol. 160, no. 4, pp. 829-837, 1989.

[125] V. Lekea-Karanika, C. Tzoumaka-Bakoula, and J. Golding, "Previous obstetric history and subsequent preterm delivery in Greece," European Journal of Obstetrics Gynecology and Reproductive Biology, vol. 37, no. 2, pp. 99-109, 1990.

[126] Y. J. Li and Y. S. Zhou, "Study of factors associated with preterm delivery," Zhongjua Liu Xing Bing Xue Za Chi, vol. 11, no. 4, pp. 229-234, 1990.

[127] J. H. Harger, A. W. Hsing, R. E. Tuomala et al., "Risk factors for preterm premature rupture of fetal membranes: a multicenter case-control study," American Journal of Obstetrics and Gynecology, vol. 163, no. 1, part 1, pp. 130-137, 1990.

[128] J. A. McGregor, J. I. French, R. Richter et al., "Antenatal microbiologic and maternal risk factors associated with prematurity," American Journal of Obstetrics and Gynecology, vol. 163, no. 5, part 1, pp. 1465-1473, 1990.

[129] R. M. Pickering and J. J. Deeks, "Risks of delivery during the 20th to 36th week of gestation," International Journal of Epidemiology, vol. 20, no. 2, pp. 456-466, 1991.

[130] J. Zhang and D. A. Savitz, "Preterm birth subtypes among blacks and whites," Epidemiology, vol. 3, no. 5, pp. 428-433, 1992.

[131] R. Michielutte, J. M. Ernest, M. L. Moore et al., "A comparison of risk assessment models for term and preterm low birthweight," Preventive Medicine, vol. 21, no. 1, pp. 98-109, 1992.

[132] J. H. Gong, "Preterm delivery and its risk factors," Zhounghua Fu Chan Ke Za Chi, vol. 27, no. 1, pp. 22-24, 1992.

[133] M. T. Mandelson, C. B. Maden, and J. R. Daling, "Low birth weight in relation to multiple induced abortions," American Journal of Public Health, vol. 82, no. 3, pp. 391-394, 1992.

[134] J. Lumley, “The epidemiology of preterm birth," Bailliere's Clinical Obstetrics and Gynaecology, vol. 7, no. 3, pp. 477-498, 1993.

[135] C. Algert, C. Roberts, P. Adelson, and M. Frommer, "Low birthweight in NSW, 1987: a population-based study," Australian and New Zealand Journal of Obstetrics and Gynaecology, vol. 33, no. 3, pp. 243-248, 1993.

[136] E. E. Ekwo, C. A. Gosselink, and A. Moawad, "Previous pregnancy outcomes and subsequent risk of preterm rupture 
of amniotic sac membranes," British Journal of Obstetrics and Gynaecology, vol. 100, no. 6, pp. 536-541, 1993.

[137] V. Lekea-Karanika and C. Tzoumaka-Bakoula, "Past obstetric history of the mother and its association with low birthweight of a subsequent child: a population based study," Paediatric and Perinatal Epidemiology, vol. 8, no. 2, pp. 173-187, 1994.

[138] D. A. Guinn, R. L. Goldenberg, J. C. Hauth, W. W. Andrews, E. Thorn, and R. Romero, "Risk factors for the development of preterm premature rupture of the membranes after arrest of preterm labor," American Journal of Obstetrics and Gynecology, vol. 173, no. 4, pp. 1310-1315, 1995.

[139] S. L. Hillier, R. P. Nugent, D. A. Eschenbach et al., "Association between bacterial vaginosis and preterm delivery of a low-birthweight infant," The New England Journal of Medicine, vol. 333, no. 26, pp. 1737-1742, 1995.

[140] A. K. Khalil, S. M. El-Amrawy, A. G. Ibrahim et al., "Pattern of growth and development of premature children at the age of two and three years in Alexandria, Egypt," Eastern Mediterranean Health Journal, vol. 1, no. 2, pp. 186-193, 1995.

[141] P. J. Meis, R. Michielutte, T. J. Peters et al., "Factors associated with preterm birth in Cardiff, Wales: I. Univariable and multivariable analysis," American Journal of Obstetrics and Gynecology, vol. 173, no. 2, pp. 590-596, 1995.

[142] J. M. Lang, E. Lieberman, and A. Cohen, "A comparison of risk factors for preterm labor and term smal-for-gestational-age birth," Epidemiology, vol. 7, no. 4, pp. 369-376, 1996.

[143] R. Hagan, H. Benninger, D. Chiffings, S. Evans, and N. French, "Very preterm birth: a regional study. Part 1: maternal and obstetric factors," British Journal of Obstetrics and Gynaecology, vol. 103, no. 3, pp. 230-238, 1996.

[144] C. P. Chen, K. G. Wang, Y. C. Yang, and L. C. See, "Risk factors for preterm birth in an upper middle class Chinese population," European Journal of Obstetrics Gynecology and Reproductive Biology, vol. 70, no. 1, pp. 53-59, 1996.

[145] G. Jacobsen, B. Schei, and L. S. Bakketeig, "Prepregnant reproductive risk and subsequent birth outcome among Scandinavian parous women," Norsk Epidemiologi, vol. 7, no. 1, pp. 33-39, 1997.

[146] J. Lumley, “The association between prior spontaneous abortion, prior induced abortion and preterm birth in first singleton births," Prenatal and Neonatal Medicine, vol. 3, no. 1, pp. 21-24, 1998.

[147] J. A. Martius, T. Steck, M. K. Oehler, and K. H. Wulf, "Risk factors associated with preterm $(<37+0$ weeks $)$ and early preterm birth $(<32+0$ weeks): univariate and multivariate analysis of 106345 singleton births from the 1994 statewide perinatal survey of Bavaria," European Journal of Obstetrics Gynecology and Reproductive Biology, vol. 80, no. 2, pp. 183-189, 1998.

[148] Small Babies in Scotland A Ten Year Overview 1987-1996, Information and Statistics Division, The National Health Service in Scotland, Scottish Program for Clinical Effectiveness, Edinburgh, UK, 1998.

[149] K. S. Lee, W. C. Lee, K. H. Meng, Lee Ch, and S. P. Kim, "Maternal factors associated with the premature rupture of membrane in the low birth weight infant deliveries," Korean Journal of Preventive Medicine, vol. 21, no. 2, pp. 207-216, 1998.

[150] P. Y. Ancel, M. J. Saurel-Cubizolles, G. C. Di Renzo, E. Papiernik, and G. Breart, "Very and moderate preterm births: are the risk factors different?" British Journal of Obstetrics and Gynaecology, vol. 106, no. 11, pp. 1162-1170, 1999.
[151] W. Zhou, H. T. Sørensen, and J. Olsen, "Induced abortion and subsequent pregnancy duration," Obstetrics and Gynecology, vol. 94, no. 6, pp. 948-953, 1999.

[152] P. Y. Ancel, M. J. Saurel-Cubizolles, G. C. Di Renzo, E. Papiernik, and G. Bréart, "Social differences of very preterm birth in Europe: interaction with obstetric history," American Journal of Epidemiology, vol. 149, no. 10, pp. 908-915, 1999.

[153] L. Foix-L'Helias and B. Blondel, "Changes in risk factors of preterm delivery in France between 1981 and 1995," Paediatric and Perinatal Epidemiology, vol. 14, no. 4, pp. 314-323, 2000.

[154] L. Foix-'Helias, P. Y. Ancel, and B. Blondel, "Risk factors for prematurity in France and comparisons between spontaneous prematurity and induced labor: results from the National Perinatal Survey 1995," Journal de Gynécologie, Obstétrique et Biologie de la Reproduction, vol. 29, no. 1, pp. 55-65, 2000.

[155] J. Gardosi and A. Francis, "Early pregnancy predictors of preterm birth: the role of a prolonged menstruation-conception interval," British Journal of Obstetrics and Gynaecology, vol. 107, no. 2, pp. 228-237, 2000.

[156] H. Bettiol, R. J. Rona, S. Chinn, M. Goldani, and M. A. Barbieri, "Factors associated with preterm births in Southeast Brazil: a comparison of two birth cohorts born 15 years apart," Paediatric and Perinatal Epidemiology, vol. 14, no. 1, pp. 30-38, 2000.

[157] P. Y. Ancel, M. J. Saurel-Cubizolles, G. C. Di Renzo, E. Papiernik, and G. Bréart, "Risk factors for 14-21 week abortions: a casecontrol study in Europe," Human Reproduction, vol. 15, no. 11, pp. 2426-2432, 2000.

[158] G. Letamo and R. G. Majelantle, "Factors influencing low birth weight and prematurity in Botswana," Journal of Biosocial Science, vol. 33, no. 3, pp. 391-403, 2001.

[159] L. Henriet and M. Kaminski, "Impact of induced abortions on subsequent pregnancy outcome: the 1995 French national perinatal survey," British Journal of Obstetrics and Gynaecology, vol. 108, no. 10, pp. 1036-1042, 2001.

[160] I. Grimmer, C. Bührer, J. W. Dudenhausen et al., "Preconceptional factors associated with very low birthweight delivery in East and West Berlin: a case control study," BMC Public Health, vol. 2, no. 1, article 10, 2002.

[161] B. Balaka, S. Boeta, A. D. Aghere, K. Boko, K. Kessie, and K. Assimadi, "Risk factors associated with prematurity at the University of Lme, Togo," Bulletin de la Société de Pathologie Exotique, vol. 95, no. 4, pp. 280-283, 2002.

[162] W. H. Han, L. M. Chen, and C. Y. Li, "Incidences of and predictors for preterm births and low birth weight infants in Taiwan," Chinese Electronic Periodical Services, pp. 131-141, 2003.

[163] A. Y. El-Bastawissi, T. K. Sorensen, C. K. Akafomo, I. O. Frederick, R. Xiao, and M. A. Williams, "History of fetal loss and other adverse pregnancy outcomes in relation to subsequent risk of preterm delivery," Maternal and Child Health Journal, vol. 7, no. 1, pp. 53-58, 2003.

[164] B. Reime, B. A. Schuecking, and P. Wenzlaff, "Perinatal outcomes of teenage pregnancies according to gravidity and obstetric history," Annals of Epidemiology, vol. 14, no. 8, pp. 619-619, 2004

[165] P. Y. Ancel, N. Lelong, E. Papiernik, M. J. Saurel-Cubizolles, and M. Kaminski, "History of induced abortion as a risk factor for preterm birth in European countries: results of the EUROPOP survey," Human Reproduction, vol. 19, no. 3, pp. 734-740, 2004.

[166] O. U. J. Umeora, A. B. A. Ande, S. O. Onuh, P. O. Okubor, and J. O. Mbazor, "Incidence and risk factors for preterm delivery in a 
tertiary health institution in Nigeria," Journal of Obstetrics and Gynaecology, vol. 24, no. 8, pp. 895-896, 2004.

[167] C. Moreau, M. Kaminski, P. Y. Ancel et al., "Previous induced abortions and the risk of very preterm delivery: results of the EPIPAGE study," BJOG: An International Journal of Obstetrics and Gynaecology, vol. 112, no. 4, pp. 430-437, 2005.

[168] A. Conde-Agudelo, J. M. Belizán, R. Breman, S. C. Brockman, and A. Rosas-Bermudez, "Effect of the interpregnancy interval after an abortion on maternal and perinatal health in Latin America," International Journal of Gynecology and Obstetrics, vol. 89, supplement 1, pp. S34-S40, 2005.

[169] P. Stang, A. O. Hammond, and P. Bauman, "Induced abortion increases the risk of very preterm delivery: results from a large perinatal database," Fertility and Sterility, vol. 84, supplement 1, p. S159, 2005.

[170] S. J. Etuk, I. S. Etuk, and A. E. Oyo-Ita, "Factors influencing the incidence of pre-term birth in Calabar, Nigeria," Nigerian Journal of Physiological Sciences, vol. 20, no. 1-2, pp. 63-68, 2005.

[171] P. Poikkeus, L. Unkila-Kallio, S. Vilska et al., "Impact of infertility characteristics and treatment modalities on singleton pregnancies after assisted reproduction," Reproductive BioMedicine Online, vol. 13, no. 1, pp. 135-144, 2006.

[172] S. A. Al-Dabbagh and W. Y. Al-Taee, "Risk factors for preterm birth in Iraq: a case-control study," BMC Pregnancy and Childbirth, vol. 6, article 13, 2006.

[173] K. K. Roy, J. Baruah, S. Kumar, N. Malhotra, A. K. Deorari, and J. B. Sharma, "Maternal antenatal profile and immediate neonatal outcome in VLBW and ELBW babies," Indian Journal of Pediatrics, vol. 73, no. 8, pp. 669-673, 2006.

[174] G. C. S. Smith, I. Shah, I. R. White, J. P. Pell, J. A. Crossley, and R. Dobbie, "Maternal and biochemical predictors of spontaneous preterm birth among nulliparous women: a systematic analysis in relation to the degree of prematurity," International Journal of Epidemiology, vol. 35, no. 5, pp. 1169-1177, 2006.

[175] S. Teramoto, A. Soeda, Y. Hayashi, and M. Urashima, "Physical and socioeconomic predictors of birthweight in Japan," Pediatrics International, vol. 48, no. 3, pp. 274-277, 2006.

[176] S. M. Losa, E. Gonzalez, and G. Gonzalez, "Risk factors for preterm birth," Progresos de Obstetricia y Ginecología, vol. 49, no. 2, pp. 57-65, 2006.

[177] F. Bruinsma, J. Lumley, J. Tan, and M. Quinn, "Precancerous changes in the cervix and risk of subsequent preterm birth," BJOG: An International Journal of Obstetrics and Gynaecology, vol. 114, no. 1, pp. 70-80, 2007.

[178] J. E. Jackson, W. A. Grobman, E. Haney, and H. Casele, "Midtrimester dilation and evacuation with laminaria does not increase the risk for severe subsequent pregnancy complications," International Journal of Gynecology and Obstetrics, vol. 96, no. 1, pp. 12-15, 2007.

[179] C. C. Lo, J. J. Hsu, C. C. Hsieh, T. T. Hsieh, and T. H. Hung, "Risk factors for spontaneous preterm delivery before 34 weeks of gestation among Taiwanese women," Taiwanese Journal of Obstetrics and Gynecology, vol. 46, no. 4, pp. 389-394, 2007.

[180] A. E. Curry, I. Vogel, C. Drews et al., "Mid-pregnancy maternal plasma levels of interleukin 2, 6, and 12, tumor necrosis factor-alpha, interferon-gamma, and granulocyte-macrophage colony-stimulating factor and spontaneous preterm delivery," Acta Obstetricia et Gynecologica Scandinavica, vol. 86, no. 9, pp. 1103-1110, 2007.

[181] J. S. Brown, T. Adera, and S. W. Masho, "Previous abortion and the risk of low birth weight and preterm births," Journal of
Epidemiology and Community Health, vol. 62, no. 1, pp. 16-22, 2008.

[182] B. Reime, B. A. Schücking, and P. Wenzlaff, "Reproductive outcomes in adolescents who had a previous birth or an induced abortion compared to adolescents' first pregnancies," $B M C$ Pregnancy and Childbirth, vol. 8, article 4, 2008.

[183] M. Voigt, D. Olbertz, C. Fusch, D. Krafczyk, V. Briese, and K. T. M. Schneider, "The influence of previous pregnancy terminations, miscarriages and still-births on the incidence of babies with low birth weight and premature births as well as a somatic classification of new borns," Zeitschrift fur Geburtshilfe und Neonatologie, vol. 212, no. 1, pp. 5-12, 2008.

[184] S. Badshah, L. Mason, K. McKelvie, R. Payne, and P. J. G. Lisboa, "Risk factors for low birthweight in the public-hospitals at Peshawar, NWFP-Pakistan," BMC Public Health, vol. 8, article 197, 2008.

[185] J. Visintine, V. Berghella, D. Henning, and J. Baxter, "Cervical length for prediction of preterm birth in women with multiple prior induced abortions," Ultrasound in Obstetrics and Gynecology, vol. 31, no. 2, pp. 198-200, 2008.

[186] R. Freak-Poli, A. Chan, G. Tucker, and J. Street, "Previous abortion and risk of pre-term birth: a population study," Journal of Maternal-Fetal and Neonatal Medicine, vol. 22, no. 1, pp. 1-7, 2009.

[187] M. Voigt, W. Henrich, M. Zygmunt, K. Friese, S. Straube, and V. Briese, "Is induced abortion a risk factor in subsequent pregnancy?" Journal of Perinatal Medicine, vol. 37, no. 2, pp. 144-149, 2009.

[188] W. Yuan, A. M. Duffner, L. Chen, L. P. Hunt, S. M. Sellers, and A. L. Bernal, "Analysis of preterm deliveries below 35 weeks' gestation in a tertiary referral hospital in the UK. A case-control survey," BMC Research Notes, vol. 3, article 119, 2010.

[189] L. F. Watson, J. A. Rayner, J. King, D. Jolley, D. Forster, and J. Lumley, "Modelling prior reproductive history to improve prediction of risk for very preterm birth," Paediatric and Perinatal Epidemiology, vol. 24, no. 5, pp. 402-415, 2010.

[190] L. F. Watson, J. A. Rayner, J. King, D. Jolley, D. Forster, and J. Lumley, "Modelling sequence of prior pregnancies on subsequent risk of very preterm birth," Paediatric and Perinatal Epidemiology, vol. 24, no. 5, pp. 416-423, 2010.

[191] A. M. Alfadhli, A. M. Hajia, F. A. K. Mohammed, H. A. Alfadhli, and M. K. El-Shazly, "Incidence and potential risk factors of low birth weight among full term deliveries," Alexandria Journal of Medicine, vol. 46, no. 2, pp. 157-164, 2010.

[192] S. Bhattacharya, A. Lowitt, E. A. Raja, A. J. Lee et al., "Maternal and perinatal outcomes following induced abortion," Human Reproduction, vol. 26, supplement 1, article i11, 2011.

[193] M. F. de Almeida, G. P. Alencar, D. Schoeps, H. M. D. Novaes, O. Campbell, and L. C. Rodrigues, "Survival and risk factors for neonatal mortality in a cohort of very low birth weight infants in the Southern region of São Paulo City, Brazil," Cadernos de Saude Publica, vol. 27, no. 6, pp. 1088-1098, 2011.

[194] H. Liao, Q. Wei, L. Duan, J. Ge, Y. Zhou, and W. Zeng, "Repeated medical abortions and the risk of preterm birth in the subsequent pregnancy," Archives of Gynecology and Obstetrics, vol. 284, no. 3, pp. 579-586, 2011.

[195] G. C. D. Renzo, I. Giardina, A. Rosati, G. Clerici, M. Torricelli et al., "Maternal risk factors for preterm birth: a country based population analysis," European Journal of Obstetrics and Gynecology and Reproductive Biology, vol. 159, no. 2, pp. 342-346, 2011. 
[196] L. F. Watson, J. A. Rayner, and D. Forster, "Identifying risk factors for very preterm birth: a reference for clinicians," Midwifery. In press.

[197] R. Klemetti, M. Gissler, M. Niinimaäki, and E. Hemminki, "Birth outcomes after induced abortion: a nationwide registerbased study of first births inFinland," Human Reproduction. In press.

[198] J. Brind, V. M. Chinchilli, M. Melbye, J. Wohlfahrt, and P. K. Andersen, "Induced abortion and risk of breast cancer," Epidemiology, vol. 11, no. 2, pp. 234-235, 2000.

[199] V. Beral, D. Bull, R. Doll, R. Peto, G. Reeves, and Collaborative Group on Hormonal Factors in Breast Cancer, "Breast cancer and abortion: collaborative reanalysis of data from 53 epidemiological studies, including 83,000 women with breast cancer from 16 countries," The Lancet, vol. 363, no. 9414, pp. 1007-1016, 2004.

[200] S. Allanson and J. Astbury, "Attachment style and broken attachments: violence, pregnancy, and abortion," Australian Journal of Psychology, vol. 53, no. 3, pp. 146-151, 2001.

[201] H. Amaro, B. Zuckerman, and H. Cabral, "Drug use among adolescent mothers: profile of risk," Pediatrics, vol. 84, no. 1, pp. 144-151, 1989.

[202] W. Barnett, N. Freudenberg, and R. Wille, "Partnership after induced abortion: a prospective controlled study," Archives of Sexual Behavior, vol. 21, no. 5, pp. 443-455, 1992.

[203] F. Bianchi-Demicheli, E. Perrin, F. Lüdicke, P. G. Bianchi, D. Chatton, and A. Campana, "Termination of pregnancy and women's sexuality," Gynecologic and Obstetric Investigation, vol. 53, no. 1, pp. 48-53, 2002.

[204] H. C. Boesen, C. Rørbye, M. Nørgaard, and L. Nilas, "Sexual behavior during the first eight weeks after legal termination of pregnancy," Acta Obstetricia et Gynecologica Scandinavica, vol. 83, no. 12, pp. 1189-1192, 2004.

[205] C. F. Bradley, "Abortion and subsequent pregnancy," Canadian Journal of Psychiatry, vol. 29, no. 6, pp. 494-498, 1984.

[206] Z. Bradshaw and P. Slade, "The effects of induced abortion on emotional experiences and relationships: a critical review of the literature," Clinical Psychology Review, vol. 23, no. 7, pp. 929-958, 2003.

[207] Z. Bardshaw and P. Slade, "The relationships between induced abortion, attitudes towards sexuality and sexual problems," Sexual and Relationship Therapy, vol. 20, no. 4, pp. 391-406, 2005.

[208] A. N. Broen, T. Moum, A. S. Bödtker, and O. Ekeberg, "Psychological impact on women of miscarriage versus induced abortion: a 2-year follow-up study," Psychosomatic Medicine, vol. 66, no. 2, pp. 265-271, 2004.

[209] A. N. Broen, T. Moum, A. S. Bødtker, and O. Ekeberg, "The course of mental health after miscarriage and induced abortion: a longitudinal, five-year follow-up study," BMC Medicine, vol. 3, article 18, 2005.

[210] A. N. Broen, T. Moum, A. S. Bödtker, and O. Ekeberg, "Reasons for induced abortion and their relation to women's emotional distress: a prospective, two-year follow-up study," General Hospital Psychiatry, vol. 27, no. 1, pp. 36-43, 2005.

[211] A. N. Broen, T. Moum, A. S. Bödtker, and O. Ekeberg, "Predictors of anxiety and depression following pregnancy termination: a longitudinal five-year follow-up study," Acta Obstetricia et Gynecologica Scandinavica, vol. 85, no. 3, pp. 317-323, 2006.
[212] G. M. Burnell and M. A. Norfleet, "Women's self-reported responses to abortion," The Journal of Psychology, vol. 121, no. 1, pp. 71-76, 1987.

[213] C. Butler, "Late psychological sequelae of abortion: questions from a primary care perspective," Journal of Family Practice, vol. 43, no. 4, pp. 396-401, 1996.

[214] N. B. Campbell, K. Franco, and S. Jurs, "Abortion in adolescence," Adolescence, vol. 23, no. 92, pp. 813-823, 1988.

[215] C. L. Cohan, C. Dunkel-schetter, and J. Lydon, "Pregnancy decision making: predictors of early stress and adjustment," Psychology of Women Quarterly, vol. 17, no. 2, pp. 223-239, 1993.

[216] P. K. Coleman, "Resolution of unwanted pregnancy during adolescence through abortion versus childbirth: individual and family predictors and psychological consequences," Journal of Youth and Adolescence, vol. 35, no. 6, pp. 903-911, 2006.

[217] P. K. Coleman, C. D. Maxey, V. M. Rue, and C. T. Coyle, "Associations between voluntary and involuntary forms of perinatal loss and child maltreatment among low-income mothers," Acta Paediatrica, International Journal of Paediatrics, vol. 94, no. 10, pp. 1476-1483, 2005.

[218] P. K. Coleman and E. S. Nelson, "The quality of abortion decisions and college students' reports of post-abortion emotional sequelae and abortion attitudes," Journal of Social and Clinical Psychology, vol. 17, no. 4, pp. 425-442, 1998.

[219] P. K. Coleman, D. C. Reardon, and J. Cougle, "The quality of the caregiving environment and child development outcomes associated with maternal history of abortion using the NLSY data," Journal of Child Psychology and Psychiatry and Allied Disciplines, vol. 43, no. 6, pp. 743-757, 2002.

[220] P. K. Coleman, D. C. Reardon, and J. R. Cougle, "Substance use among pregnant women in the context of previous reproductive loss and desire for current pregnancy," British Journal of Health Psychology, vol. 10, no. 2, pp. 255-268, 2005.

[221] P. K. Coleman, D. C. Reardon, V. M. Rue, and J. Cougle, "A history of induced abortion in relation to substance use during subsequent pregnancies carried to term," American Journal of Obstetrics and Gynecology, vol. 187, no. 6, pp. 1673-1678, 2002.

[222] P. K. Coleman, D. C. Reardon, V. M. Rue, and J. Cougle, "State-funded abortions versus deliveries: a comparison of outpatient mental health claims over 4 years," American Journal of Orthopsychiatry, vol. 72, no. 1, pp. 141-152, 2002.

[223] P. K. Coleman, D. C. Reardon, T. Strahan, and J. R. Cougle, "The psychology of abortion: a review and suggestions for future research," Psychology and Health, vol. 20, no. 2, pp. 237-271, 2005.

[224] G. K. Congleton and L. G. Calhoun, "Post-abortion perceptions: a comparison of self-identified distressed and nondistressed populations," International Journal of Social Psychiatry, vol. 39, no. 4, pp. 255-265, 1993.

[225] G. K. Congleton and L. G. Calhoun, "Post-abortion perceptions: a comparison of self-identified distressed and nondistressed populations," International Journal of Social Psychiatry, vol. 39, no. 4, pp. 255-265, 1993.

[226] M. P. Conklin and B. P. O'Connor, "Beliefs about the fetus as a moderator of post-abortion psychological well-being," Journal of Social and Clinical Psychology, vol. 14, no. 1, pp. 76-95, 1995.

[227] D. Côté-Arsenault and M. T. B. Dombeck, "Maternal assignment of fetal personhood to a previous pregnancy loss: relationship to anxiety in the current pregnancy," Health Care for Woman International, vol. 22, no. 7, pp. 649-665, 2001. 
[228] J. R. Cougle, D. C. Reardon, and P. K. Coleman, "Depression associated with abortion and childbirth: a long-term analysis of the NLSY cohort," Medical Science Monitor, vol. 9, no. 4, pp. CR105-CR112, 2003.

[229] J. R. Cougle, D. C. Reardon, and P. K. Coleman, "Generalized anxiety following unintended pregnancies resolved through childbirth and abortion: a cohort study of the 1995 National Survey of Family Growth," Journal of Anxiety Disorders, vol. 19, no. 1, pp. 137-142, 2005.

[230] C. Cozzarelli, "Personality and self-efficacy as predictors of coping with abortion," Journal of Personality and Social Psychology, vol. 65, no. 6, pp. 1224-1236, 1993.

[231] H. P. David, N. K. Rasmussen, and E. Holst, "Postpartum and postabortion psychotic reactions," Family Planning Perspectives, vol. 13, no. 2, pp. 88-91, 1981.

[232] F. O. Fatoye, A. B. Adeyemi, and B. Y. Oladimeji, "Emotional distress and its correlates among Nigerian women in late pregnancy," Journal of Obstetrics and Gynaecology, vol. 24, no. 5, pp. 504-509, 2004.

[233] D. M. Fergusson, L. J. Horwood, and E. M. Ridder, "Abortion in young women and subsequent mental health," Journal of Child Psychology and Psychiatry and Allied Disciplines, vol. 47, no. 1, pp. 16-24, 2006.

[234] D. M. Fergusson, L. J. Horwood, and J. M. Boden, "Reactions to abortion and subsequent mental health," British Journal of Psychiatry, vol. 195, no. 5, pp. 420-426, 2009.

[235] S. L. Fielding and E. A. Schaff, "Social context and the experience of a sample of U.S. women taking RU-486 (mifepristone) for early abortion," Qualitative Health Research, vol. 14, no. 5, pp. 612-627, 2004.

[236] W. Franz and D. Reardon, "Differential impact of abortion on adolescents and adults," Adolescence, vol. 27, no. 105, pp. 161-172, 1992.

[237] M. Gissler, E. Hemminki, and J. Lönnqvist, "Suicides after pregnancy in Finland, 1987-94: register linkage study," British Medical Journal, vol. 313, no. 7070, pp. 1431-1434, 1996.

[238] M. Gissler, C. Berg, M. H. Bouvier-Colle, and P. Buekens, "Injury deaths, suicides and homicides associated with pregnancy, Finland 1987-2000," European Journal of Public Health, vol. 15, no. 5, pp. 459-463, 2005.

[239] E. Guilbert and D. Roter, "Assessment of satisfaction with induced abortion procedure," The Journal of Psychology, vol. 131, no. 2, pp. 157-166, 1997.

[240] B. L. Harlow, L. S. Cohen, M. W. Otto, D. Spiegelman, and D. W. Cramer, "Early life menstrual characteristics and pregnancy experiences among women with and without major depression: the Harvard study of moods and cycles," Journal of Affective Disorders, vol. 79, no. 1-3, pp. 167-176, 2004.

[241] A. Hemmerling, F. Siedentopf, and H. Kentenich, "Emotional impact and acceptability of medical abortion with mifepristone: a German experience," Journal of Psychosomatic Obstetrics and Gynecology, vol. 26, no. 1, pp. 23-31, 2005.

[242] R. Henshaw, S. Naji, I. Russell, and A. Templeton, "Psychological responses following medical abortion (using mifepristone and gemeprost and surgical vacuum aspiration: a patientcentered, partially randomised prospective study," Acta Obstetricia et Gynecologica Scandinavica, vol. 73, no. 10, pp. 812-818, 1994.

[243] A. Hittner, "Feelings of well-being before and after abortion," American Mental Health Counselors Association Journal, vol. 9, pp. 98-104, 1987.
[244] T. L. Hope, E. I. Wilder, and T. T. Watt, "The relationships among adolescent pregnancy, pregnancy resolution, and juvenile delinquency," Sociological Quarterly, vol. 44, no. 4, pp. 555-576, 2003.

[245] C. Husfeldt, S. K. Hansen, A. Lynberg, M. Noddebo, and B. Petersson, "Ambivalence among women applying for abortion," Acta Obstetricia et Gynecologica Scandinavica, vol. 74, no. 10, pp. 813-817, 1995.

[246] A. Kero, U. Högberg, L. Jacobsson, and A. Lalos, "Legal abortion: a painful necessity," Social Science and Medicine, vol. 53, no. 11, pp. 1481-1490, 2001.

[247] A. Kero, U. Högberg, and A. Lalos, "Wellbeing and mental growth-long-term effects of legal abortion," Social Science and Medicine, vol. 58, no. 12, pp. 2559-2569, 2004.

[248] A. Kero and A. Lalos, "Ambivalence-a logical response to legal abortion: a prospective study among women and men," Journal of Psychosomatic Obstetrics and Gynaecology, vol. 21, no. 2, pp. 81-91, 2000.

[249] T. Kitamura, M. A. Toda, S. Shima, and M. Sugawara, "Single and repeated elective abortions in Japan: a psychosocial study," Journal of Psychosomatic Obstetrics and Gynaecology, vol. 19, no. 3, pp. 126-134, 1998.

[250] P. Lauzon, D. Roger-Achim, A. Achim, and R. Boyer, "Emotional distress among couples involved in first-trimester induced abortions," Canadian Family Physician, vol. 46, pp. 2033-2040, 2000.

[251] A. Lazarus and R. Stern, "Psychiatric aspects of pregnancy termination," Clinics in Obstetrics and Gynaecology, vol. 13, no. 1, pp. 125-134, 1986.

[252] A. Lazarus, "Psychiatric sequelae of legalized elective first trimester abortion," Journal of Psychosomatic Obstetrics and Gynecology, vol. 4, no. 3, pp. 141-150, 1985.

[253] J. P. Lemkau, "Emotional sequelae of abortion: implications for clinical practice," Psychology of Women Quarterly, vol. 12, no. 4, pp. 461-472, 1988.

[254] W. J. Lewis, "Factors associated with post-abortion adjustment problems: implications for triage," Canadian Journal of Human Sexuality, vol. 6, no. 1, pp. 9-16, 1997.

[255] S. P. Llewelyn and R. Pytches, "An investigation of anxiety following termination of pregnancy," Journal of Advanced Nursing, vol. 13, no. 4, pp. 468-471, 1988.

[256] K. M. Lodl, A. Mcgettigan, and J. Bucy, "Women's responses to abortion: implications for post-abortion support groups," Journal of Social Work and Human Sexuality, vol. 3, no. 2-3, pp. 119-132, 1985.

[257] J. Lydon, C. Dunkel-Schetter, C. L. Cohan, and T. Pierce, "Pregnancy decision making as a significant life event: a commitment approach," Journal of Personality and Social Psychology, vol. 71, no. 1, pp. 141-151, 1996.

[258] P. Mueller and B. Major, "Self-blame, self-efficacy, and adjustment to abortion," Journal of Personality and Social Psychology, vol. 57, no. 6, pp. 1059-1068, 1989.

[259] B. Major, C. Cozzarelli, M. L. Cooper et al., "Psychological responses of women after first-trimester abortion," Archives of General Psychiatry, vol. 57, no. 8, pp. 777-784, 2000.

[260] B. Major, C. Cozzarelli, A. M. Sciacchitano, M. L. Cooper, M. Testa, and P. M. Mueller, "Perceived social support, self-efficacy, and adjustment to abortion," Journal of Personality and Social Psychology, vol. 59, no. 3, pp. 452-463, 1990.

[261] B. Major and R. H. Gramzow, "Abortion as stigma: cognitive and emotional implications of concealment," Journal of Personality and Social Psychology, vol. 77, no. 4, pp. 735-745, 1999. 
[262] W. B. Miller, "An empirical study of the psychological antecedents and consequences of induced abortion," Journal of Social Issues, vol. 48, pp. 67-93, 1992.

[263] W. B. Miller, D. J. Pasta, and C. L. Dean, “Testing a model of the psychological consequences of abortion," in the New Civil War: The Psychology, Culture, and Politics of Abortion, L. J. Beckman and S. M. Harvey, Eds., American Psychological Association, Washington, DC, USA, 1998.

[264] C. L. Morgan, M. Evans, and J. R. Peters, "Suicides after pregnancy. Mental health may deteriorate as a direct effect of induced abortion," British Medical Journal, vol. 314, no. 7084, pp. 902-903, 1997.

[265] D. T. Moseley, D. R. Follingstad, H. Harley, and R. V. Heckel, "Psychological factors that predict reaction to abortion," Journal of Clinical Psychology, vol. 37, no. 2, pp. 276-279, 1981.

[266] N. Mufel, A. Speckhard, and S. Sivuha, "Predictors of posttraumatic stress disorder following abortion in a former soviet union country," Journal of Prenatal and Perinatal Psychology and Health, vol. 17, pp. 41-61, 2002.

[267] P. G. Ney, T. Fung, and A. R. Wickett, "Relations between induced abortion and child abuse and neglect: four studies," Pre and Perinatal Psychology Journal, vol. 8, pp. 43-63, 1993.

[268] P. G. Ney, T. Fung, A. R. Wickett, and C. Beaman-Dodd, "The effects of pregnancy loss on women's health," Social Science and Medicine, vol. 38, no. 9, pp. 1193-1200, 1994.

[269] T. Østbye, E. F. Wenghofer, C. A. Woodward, G. Gold, and J. Craighead, "Health services utilization after induced abortions in Ontario: a comparison between community clinics and hospitals," American Journal of Medical Quality, vol. 16, no. 3, pp. 99-106, 2001.

[270] M. J. Patterson, R. P. Hill, and K. Maloy, "Abortion in America: a consumer-based perspective," Journal of Consumer Research, vol. 21, pp. 677-694, 1995.

[271] W. Pedersen, "Abortion and depression: a population-based longitudinal study of young women," Scandinavian Journal of Public Health, vol. 36, no. 4, pp. 424-428, 2008.

[272] W. Pedersen, "Childbirth, abortion and subsequent substance use in young women: a population-based longitudinal study," Addiction, vol. 102, no. 12, pp. 1971-1978, 2007.

[273] L. M. Pope, N. E. Adler, and J. M. Tschann, "Postabortion psychological adjustment: are minors at increased risk?" Journal of Adolescent Health, vol. 29, no. 1, pp. 2-11, 2001.

[274] E. Posavac and T. Miller, "Some problems caused by not having a conceptual foundation for health research: an illustration from studies of the psychological effects of abortion," Psychology and Health, vol. 5, pp. 13-23, 1990.

[275] N. Prommanart, S. Phatharayuttawat, D. Boriboonhirunsarn, and P. Sunsaneevithayakul, "Maternal grief after abortion and related factors," Journal of the Medical Association of Thailand, vol. 87, no. 11, pp. 1275-1280, 2004.

[276] D. C. Reardon and P. K. Coleman, "Relative treatment rates for sleep disorders and sleep disturbances following abortion and childbirth: a prospective record-based study," Sleep, vol. 29, no. 1, pp. 105-106, 2006.

[277] D. C. Reardon, P. K. Coleman, and J. R. Cougle, "Substance use associated with unintended pregnancy outcomes in the National Longitudinal Survey of Youth," American Journal of Drug and Alcohol Abuse, vol. 30, no. 2, pp. 369-383, 2004.

[278] D. C. Reardon and J. R. Cougle, "Depression and unintended pregnancy in the National Longitudinal Survey of Youth: a cohort study," British Medical Journal, vol. 324, no. 7330, pp. 151-152, 2002.
[279] D. C. Reardon and J. R. Cougle, "Depression and unintended pregnancy in the National Longitudinal Survey of Youth: a cohort study: reply," British Medical Journal, vol. 324, no. 7345, pp. 1097-1098, 2002.

[280] D. C. Reardon, J. R. Cougle, V. M. Rue, M. W. Shuping, P. K. Coleman, and P. G. Ney, "Psychiatric admissions of low-income women following abortion and childbirth," Canadian Medical Association Journal, vol. 168, no. 10, pp. 1253-1256, 2003.

[281] D. C. Reardon and P. G. Ney, "Abortion and subsequent substance abuse," American Journal of Drug and Alcohol Abuse, vol. 26, no. 1, pp. 61-75, 2000.

[282] D. C. Reardon, P. G. Ney, F. Scheuren, J. Cougle, P. K. Coleman, and T. W. Strahan, "Deaths associated with pregnancy outcome: a record linkage study of low income women," Southern Medical Journal, vol. 95, no. 8, pp. 834-841, 2002.

[283] D. I. Rees and J. J. Sabia, “The relationship between abortion and depression: new evidence from the fragile families and child wellbeing study," Medical Science Monitor, vol. 13, no. 10, pp. CR430-CR436, 2007.

[284] L. I. Remennick and R. Segal, "Socio-cultural context and women's experiences of abortion: Israeli women and Russian immigrants compared," Culture, Health and Sexuality, vol. 3, no. 1, pp. 49-66, 2001.

[285] V. M. Rue, P. K. Coleman, J. J. Rue, and D. C. Reardon, "Induced abortion and traumatic stress: a preliminary comparison of American and Russian women," Medical Science Monitor, vol. 10, no. 10, pp. SR5-SR16, 2004.

[286] L. Schleiss, K. A. Mygind, R. V. Borre, and B. H. Petersson, "Psychological consequences of induced abortion," Ugeskrift for Laeger, vol. 159, no. 23, pp. 3603-3606, 1997.

[287] S. Sivuha, "Predictors of posttraumatic stress disorder following abortion in a former Soviet Union country," Journal of Prenatal and Perinatal Psychology and Health, vol. 17, pp. 41-61, 2002.

[288] P. Slade, S. Heke, J. Fletcher, and P. Stewart, "A comparison of medical and surgical termination of pregnancy: choice, emotional impact and satisfaction with care," British Journal of Obstetrics and Gynaecology, vol. 105, no. 12, pp. 1288-1295, 1998.

[289] H. Söderberg, C. Andersson, L. Janzon, and N. O. Sjöberg, "Continued pregnancy among abortion applicants. A study of women having a change of mind," Acta Obstetricia et Gynecologica Scandinavica, vol. 76, no. 10, pp. 942-947, 1997.

[290] H. Söderberg, L. Janzon, and N. O. Sjöberg, "Emotional distress following induced abortion a study of its incidence and determinants among abortees in Malmo, Sweden," European Journal of Obstetrics Gynecology and Reproductive Biology, vol. 79, no. 2, pp. 173-178, 1998.

[291] A. Speckhard and N. Mufel, "Universal responses to abortion? Attachment, trauma, and grief in women following abortion," Journal of Prenatal and Perinatal Psychology and Health, vol. 18, no. 1, pp. 3-37, 2003.

[292] A. C. Speckhard and V. M. Rue, "Postabortion syndrome: an emerging public health concern," Journal of Social Issues, vol. 48, pp. 95-119, 1992.

[293] S. Suliman, T. Ericksen, P. Labuschgne, R. de Wit, D. J. Stein, and S. Seedat, "Comparison of pain, cortisol levels, and psychological distress in women undergoing surgical termination of pregnancy under local anaesthesia versus intravenous sedation," BMC Psychiatry, vol. 7, article 24, 2007.

[294] M. B. Tamburrino, K. N. Franco, N. B. Campbell, J. E. Pentz, C. L. Evans, and S. G. Jurs, "Postabortion dysphoria and religion," Southern Medical Journal, vol. 83, no. 7, pp. 736-738, 1990. 
[295] M. Törnbom and A. Möller, "Repeat abortion: a qualitative study," Journal of Psychosomatic Obstetrics and Gynaecology, vol. 20, no. 1, pp. 21-30, 1999.

[296] S. C. Turell, M. W. Armsworth, and J. P. Gaa, "Emotional response to abortion: a critical review of the literature," Women and Therapy, vol. 9, no. 4, pp. 49-68, 1990.

[297] D. R. Urquhart and A. A. Templeton, "Psychiatric morbidity and acceptibility following medical and surgical methods of induced abortion," British Journal of Obstetrics and Gynaecology, vol. 98, no. 4, pp. 396-399, 1991.

[298] G. B. Williams, "Short-term grief after an elective abortion," Journal of Obstetric, Gynecologic, and Neonatal Nursing, vol. 30, no. 2, pp. 174-183, 2001.

[299] G. H. Wilmoth, M. deAlteriis, and D. Bussell, "Prevalence of psychological risks following legal abortion in the U.S.: limits of the evidence," Journal of Social Issues, vol. 48, pp. 37-66, 1992.

[300] D. Yamaguchi and D. Kandel, "Drug use and other determinants of premarital pregnancy and its outcome: a dynamic analysis of competing life events," Journal of Marriage and the Family, vol. 49, pp. 257-270, 1987.

[301] P. K. Coleman, "Abortion and mental health: quantitative synthesis and analysis of research published 1995-2009," The British Journal of Psychiatry, vol. 199, no. 3, pp. 180-186, 2011.

[302] J. R. Steinberg, "Later abortions and mental health: psychological experiences of women having later abortions-a critical review of research," Women's Health Issues, vol. 21, no. 3, supplement, pp. S44-48, 2011.

[303] V. E. Charles, C. B. Polis, S. K. Sridhara, and R. W. Blum, "Abortion and long-term mental health outcomes: a systematic review of the evidence," Contraception, vol. 78, no. 6, pp. 436-450, 2008.

[304] R. K. Jones and K. Kooistra, "Abortion incidence and access to services in the United States, 2008," Perspectives on Sexual and Reproductive Health, vol. 43, no. 1, pp. 41-50, 2011.

[305] U. Landy and P. D. Darney, "The future of contraception: the future leaders of family planning," American Journal of Obstetrics and Gynecology, vol. 205, no. 4, supplement, pp. S29-S33, 2011.

[306] C. B. Jackson and A. M. Foster, "Ob/Gyn training in abortion care: results from a national survey," Contraception, vol. 86, no. 4, pp. 407-412, 2012.

[307] M. L. Evans and L. V. Backus, "Medical students for choice: creating tomorrow's abortion providers," Contraception, vol. 83, no. 5, pp. 391-393, 2011.

[308] P. B. Linton, "The legal status of abortion in the states if Roe versus Wade is overruled," Issues in Law and Medicine, vol. 23, no. 1, pp. 3-43, 2007.

[309] D. J. Oyer, "Playing politics with the doctor-patient relationshipe," The New England Journal of Medicine, vol. 366, no. 24, pp. 2326-2327, 2012.

[310] L. R. Collins and S. L. Crockin, "Fighting "personhood" initiatives in the United States," Reproductive BioMedicine Online, vol. 24, no. 7, pp. 689-691, 2012.

[311] W. Droegemuleer, R. Florio, and E. S. Taylor, “The second year's experience with Colorado abortion law," American Journal of Obstetrics and Gynecology, vol. 109, pp. 957-958, 1971. 


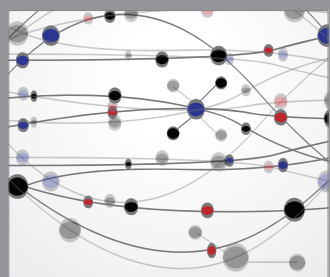

The Scientific World Journal
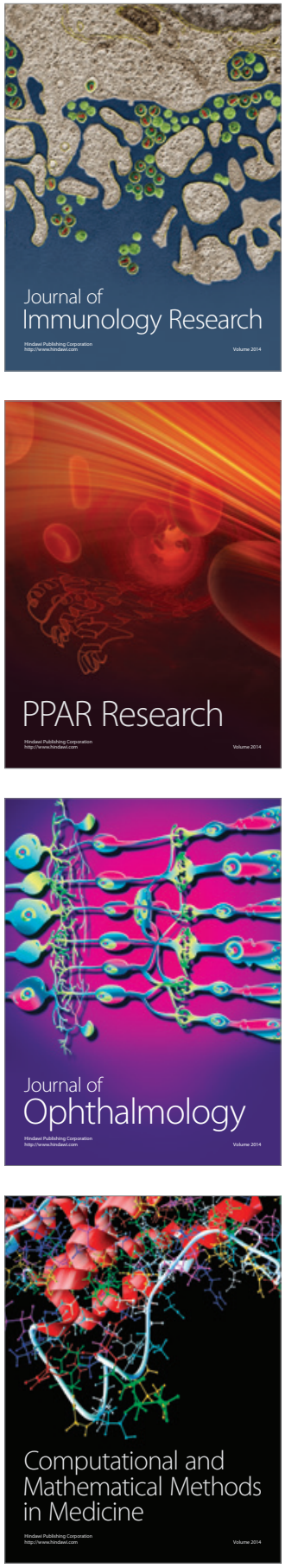

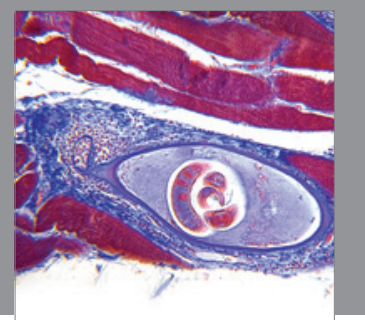

Gastroenterology

Research and Practice
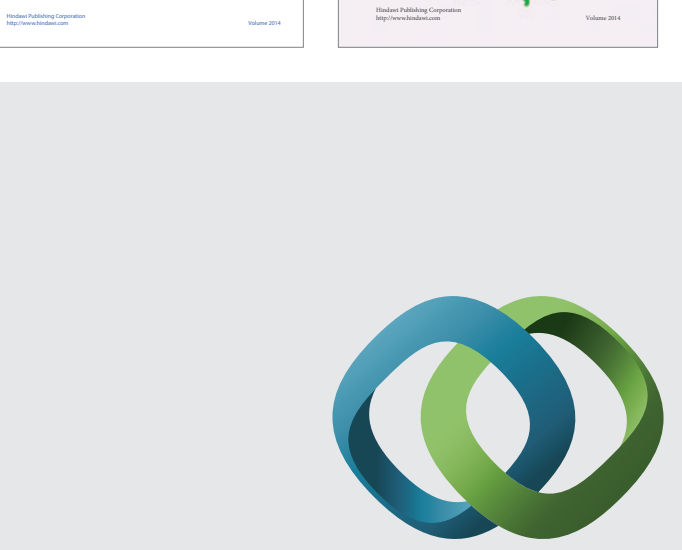

\section{Hindawi}

Submit your manuscripts at

http://www.hindawi.com
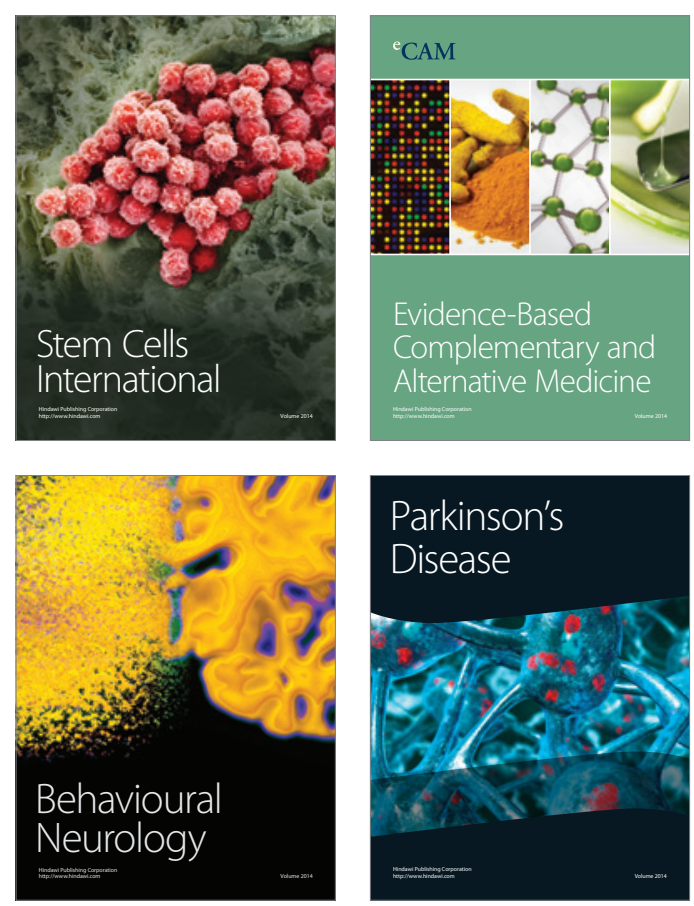

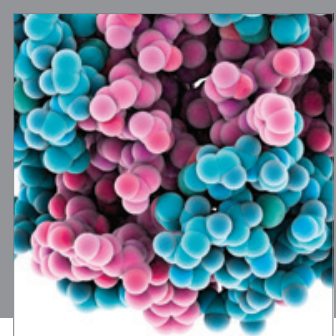

Journal of
Diabetes Research

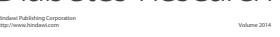

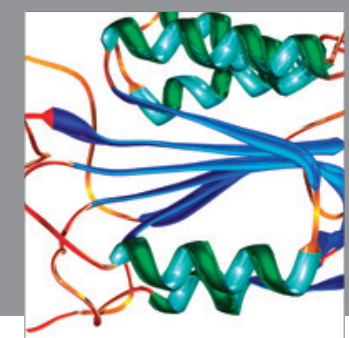

Disease Markers
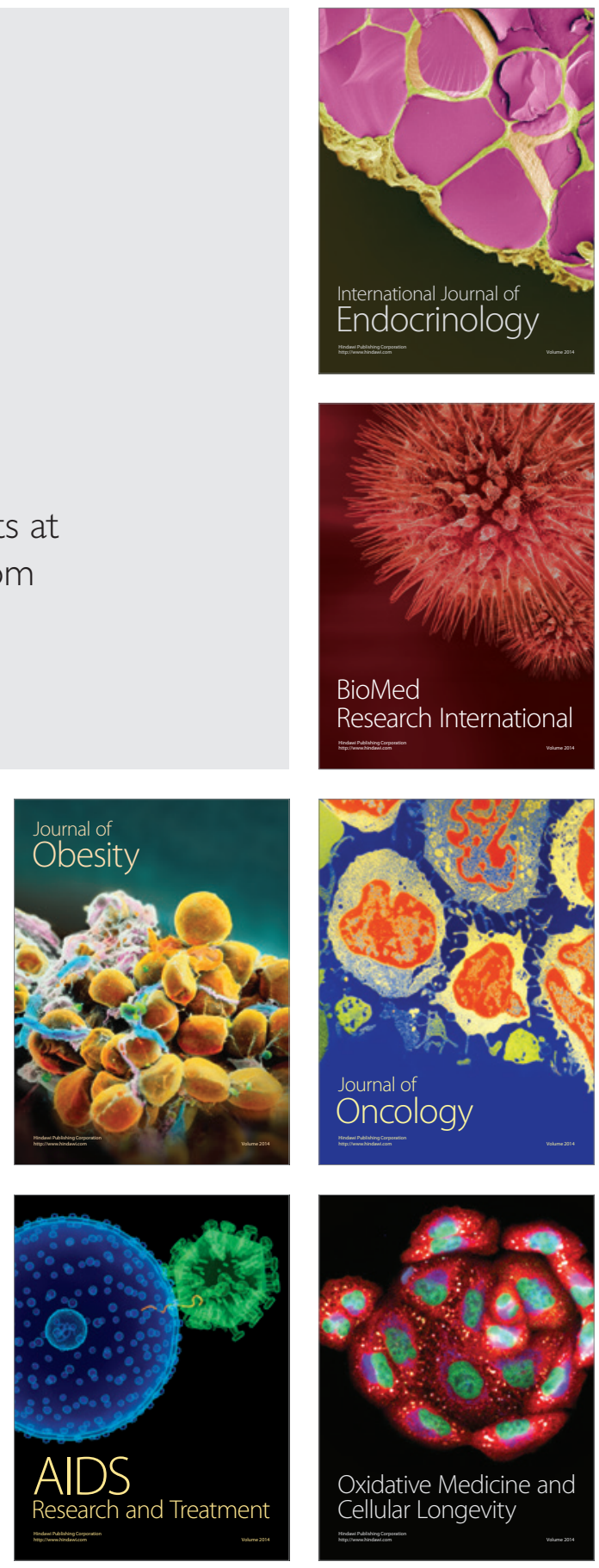